\title{
A cidade de Barreiras enquanto polo de ensino superior na região do extremo oeste da Bahia: desafios e perspectivas
}

\author{
The city of Barreiras as higher education pole in the west extreme \\ region of Bahia: challenges and perspectives
}

Elisama dos Santos da Silva', Robson Soares Brasileiro"

\section{RESUMO}

Esta pesquisa tem como objetivo principal discutir a expansão e interiorização de Instituições de Ensino Superior na cidade de Barreiras-BA, visando identificar as perspectivas e os desafios, além de interpretar como a expansão do Ensino Superior dinamiza a economia local e regional. No decorrer da referida pesquisa foi necessário uma análise sobre a implantação de Universidades no Extremo Oeste da Bahia, com ênfase na diversidade de alguns cursos superiores oferecidos pelas seguintes Instituições de Ensino Superior - IES: Universidade Federal do Oeste da Bahia - UFOB (mais os campus territorializados nas cidades de: Luís Eduardo Magalhães, Bom Jesus da Lapa e Barra); Instituto Federal da Bahia - IFBA, (campus Barreiras); Universidade do Estado da Bahia - UNEB, (campus IX); Faculdade São Francisco de Barreiras - FASB; Faculdade D. Pedro Il; Faculdade Regional da Bahia - UNIRB e Universidade Norte do Paraná - UNOPAR. Desta forma, considerando e pontuando a importância do Programa de Apoio a Planos de Reestruturação e Expansão das Universidades Federais (Reuni), nas cidades interioranas do Brasil.

Palavras-chave: Ensino superior; Expansão; Universidades

\section{ABSTRACT}

This research has as main objective to discuss the expansion and interiorization of Higher Education Institutions in the city of Barreiras-BA, aiming at identifying perspectives and challenges, as well as interpreting how the expansion of Higher Education dynamizes the local and regional economy. In the course of this research, it was necessary to analyze the implementation of Universities in the Extreme West of Bahia, with emphasis on the diversity of some higher education offered by the following Institutions of Higher Education - IES: Federal University of Western Bahia - UFOB (plus campus territorialized in the cities of: Luís Eduardo Magalhães, Bom Jesus da Lapa and Barra); Federal Institute of Bahia - IFBA, (Barreiras campus); University of the State of Bahia - UNEB, (campus IX); Faculty are Francis of Barreiras - FASB; Dom Pedro II Faculty; Regional School of Bahia - UNIRB and Northern University of Paraná - UNOPAR. Thus, considering and punctuating the importance of the Program of

I Graduanda no Curso de Licenciatura em Geografia da Universidade Federal do Oeste da Bahia e bolsista do Programa Institucional de Bolsas de Iniciação Científica - PIBIC do Conselho Nacional de Desenvolvimento Científico e Tecnológico - CNPq. E-mail: elisama.1996@gmail.com Orcid-ID: http://orcid.org/0000-0003-3725-7240 
Support for the Restructuring and Expansion Plans of the Federal Universities (Reuni), in the interior cities of Brazil.

Keywords: Higher Education; Expansion; Universities

\section{INTRODUÇÃO}

As universidades brasileiras nos últimos tempos têm contribuído de forma significativa para a ampliação do número de pessoas vinculadas ao Ensino Superior. Essa medida deve-se não somente pelas ações afirmativas desenvolvidas no próprio âmbito interno dessas instituições de fortalecerem o acesso e a permanência de estudantes de baixa renda nas Instituições de Ensino Superior, como também, as políticas públicas na área de educação que foram ampliadas nos últimos 14 anos.

Neste sentido, o Ensino Superior no Brasil se expandiu e, se interiorizou em todas as regiões brasileiras nas últimas duas décadas. Esse processo é fruto de programas como o REUNI (Programa de Apoio a Planos de Reestruturação e Expansão das Universidades Federais), PROUNI (Programa universidade para todos) e, o próprio ENEM (Exame Nacional do Ensino Médio) que possibilitaram uma maior dinâmica de procura e acesso ao Ensino Superior, principalmente nas cidades interioranas do país.

Esses programas permitiram a inserção social de estudantes de baixa renda a cursarem uma universidade de qualidade e gratuita, assim como terem acesso ao Fundo de Financiamento Estudantil-FIES, tendo como alternativa a entrada em uma IES privada. Haja vista, que em outros tempos grande parte das instituições de Ensino Superior no Brasil em sua maioria encontravam-se localizadas nas grandes regiões metropolitanas do país, com enorme concentração nas regiões Sudeste e Sul. Esse fato impossibilitava que famílias carentes no interior do Brasil enviasse seus filhos para cursarem uma universidade nas grandes cidades, devido ao alto custo de manter o filho durante quatro a seis anos na capital. Almeida (2015) enfatiza que o Ensino Superior no 
Brasil não é ofertado de forma igualitária, e as ações estão sendo firmadas com o objetivo de democratizar o acesso a esse nível educacional.

No Brasil as discussões sobre a implantação de universidades têm sido frequentes, o debate sobre essas questões tem ocupado espaço acadêmico e, as Ciências Humanas tem corroborado para a difusão de conhecimentos com implementação de pesquisas. Alicerçando esse questionamento referente a relevância das Instituições de Ensino Superior (IES) é importante ressaltar que a expansão de universidades, sejam elas públicas ou privadas, evidentemente beneficiou regiões onde essas foram implementadas, tendo em vista que esta presença refletirá nos serviços que irão ser ofertados, pois tais aspectos estimula a economia dos locais em que as instituições de ensino foram territorializadas. Sobre esse debate encontram-se na literatura pesquisas que corroboram de modo significativo para interpretação das questões direcionadas à expansão do Ensino Superior e dinamização de economias locais interioranas, como pode ser observado na citação abaixo:

Outro aspecto importante é o papel da universidade como dinamizador das economias locais e regionais onde as mesmas estão instaladas, principalmente no seu entorno, através da geração de emprego e renda, colaborando significativamente no crescimento e desenvolvimento das cidades. (GOEBEL; MIURA, 2004, p. 36).

Como visto acima os autores destacam de modo contundente o papel dessas instituições na consolidação e dinamização de economias regionais, com destaque significativo para geração de emprego e renda, além de corroborar também para as questões especulativas, principalmente naquilo que diz respeito ao setor imobiliário e uso do solo urbano.

\section{BREVE CONTEXTO HISTÓRICO DAS UNIVERSIDADES NO BRASIL}

O processo de ocupação do território brasileiro se deu inicialmente no litoral, ficando a porção das áreas interioranas desconhecidas e inacessíveis durante um bom tempo. A partir do processo de formação territorial do Brasil, as 
primeiras cidades foram surgindo desde o Rio Grande do Norte ao Sul da Bahia. Esses núcleos populacionais se deram primeiramente a partir de ciclos que evidenciaram as bases econômicas (Ciclo do Pau-Brasil, Ciclo da Cana-de-Açúcar, Ciclo do Ouro, Ciclo do Algodão, Ciclo do Café, Ciclo da Borracha), proporcionado a princípio a urbanização e relações sociais. Foram nessas primeiras cidades litorâneas, diga-se de passagem, aquelas mais expressivas em termos econômicos e concentração de decisões político-administrativa do país que irá surgir no século XX as primeiras universidades. Nesse contexto, encontra-se na literatura autores que trabalham essas questões a partir de escalas geográficas mais amplas como se confere na citação abaixo:

Em sua constituição inicial, a educação superior no Brasil era marcada apenas por instituições isoladas localizadas em algumas cidades brasileiras, a exemplo Salvador, Olinda, Rio de Janeiro, São Paulo e Ouro Preto (FREIRE; HOLANDA, 2018, p. 14).

Como pode-se constatar nas palavras dos autores acima, os primeiros cursos superiores estavam concentrados nas principais cidades do litoral do Brasil, com exceção para São Paulo e Outro Preto, ou seja, aquelas mais expressiva em termos econômicos e sociais desde o período do Brasil Colônia. Com o crescimento ao longo dos séculos acelerou-se o processo de urbanização, consequentemente foi acrescentado demandas e exigências sociais, sendo de formação para a vida como também para o mercado de trabalho.

Antes a sociedade pautada na subsistência e no escambo, a partir do surgimento do Estado e do comércio se modificou e ampliou-se, os aspectos econômicos, sendo assim, houve a territorialização das relações capitalistas de produção, exigindo qualificação e técnica. Com o surgimento do capital e das relações comerciais foi necessário a divisão do trabalho em mental e manual, dando início a aquilo que Santos (2008) denominou de Meio-Técnico-CientíficoInformacional.

O processo de urbanização de certa forma favoreceu a expansão das IES. O advento da revolução industrial intensificou esse processo na Europa e na 
América, no caso específico do Brasil, o efeito da industrialização vai se efetivar de maneira muito rudimentar com a indústria do café no começo século XIX, ainda sobre a concentração de um Brasil agrário exportador no qual as tomadas de decisões econômicas e políticas estavam concentradas no campo.

No último Censo realizado pelo IBGE em (2010) o contingente percentual de população urbana no Brasil era entorno de $85 \%$ e rural 15\%. No próximo Censo a ser realizado pelo instituto acima destacado em (2020), não restará dúvidas que o percentual de população urbana deverá ser muito maior, enquanto o de população rural deverá ser bem inferior a aquele identificado em 2010 pelo mesmo órgão de pesquisa citado anteriormente. Isso devido ao próprio processo de intensificação da industrialização e mecanização do campo, as novas relações de trabalhos que vão se pautando nas cidades e, o atrativo e fascínio que o modus de vida urbano exerce sobre as pessoas.

No Brasil, após a proclamação da república houve mudanças intensas, que, por sua vez, fez com que o Ensino Superior obtivesse uma massificação. Antes uma educação regrada para minoria, após os movimentos sociais que aconteceram no Brasil, fez com que essa situação fosse reorganizada. A história da Educação Superior Brasileira pode ser analisada em cinco grandes períodos ao longo dos séculos XIX e XX:

Se, por um lado, este modelo se manteve quase inalterado, somente no final do século XIX foram introduzidas algumas modificações no sentido de dar uma ênfase maior à formação tecnológica, por outro, o sistema de ensino superior brasileiro revelou, desde cedo, marcas de descontinuidades no que diz respeito, sobretudo, aos aspectos que envolvem sua relação com o Estado. Nesta perspectiva, é possível identificar em sua história cinco datas-chave: 1808, 1898, 1930, 1968 e 1985. (SAMPAIO, 1991, p. 1).

Durante esses períodos citados acima, ocorreram no Brasil revoluções e surgimento de manifestações coletivas que dinamizaram o cenário político, social e cultural, buscando reconhecimento dos direitos em meio a regimes de governos ditatoriais, assim como fortalecimento dos movimentos em prol do processo de redemocratização do país. 
Em 1808 o príncipe regente D. João fundou a escola de cirurgia que posteriormente foi constituída em Academia Médico Cirúrgica da Bahia, que nos dias de hoje é a faculdade de medicina da Universidade Federal da Bahia. Outra academia médico-cirúrgica foi implantada no estado do Rio de Janeiro, que posteriormente se tornou a Universidade Federal do Rio de Janeiro. Sampaio (1991) enfatiza que estas instituições escolares de formação técnica influenciaram e possibilitaram a implantação de universidades no território brasileiro. No período colonial, havia o Ensino Superior, mas não universidades, somente em 1930, obteve o status universitário.

Quando foram instaladas as primeiras escolas de Educação Básica no Brasil, o objetivo a ser alcançado foi diferenciado, na educação inicial, era pautado conhecimentos para serem vivenciados e utilizados no decorrer da vida. No Ensino Superior era induzido a produção de conhecimento científico, mas é necessário destacar que a compreensão empírica é de grande relevância para o seguimento do saber acadêmico. Quando se é discutido a escolarização no período dos jesuítas, não se pode definir como início da educação propriamente dita, no entanto, antes mesmo da Companhia de Jesus se instituísse na colônia, havia uma educação já ministrada, de antemão é necessário distinguir esse processo educacional sendo a princípio ensinamentos locais e culturais dos povos indígenas.

É importante ressaltar neste texto que embora muitos autores tomem como marco referencial a educação escolar por meio dos jesuítas, todavia, muito antes do papel deste já existiam pessoas com determinado saber letrado que ensinavam as crianças e jovens nas comunidades, vilas e arraiais. Vale ressaltar também que os nativos primeiros habitantes do Brasil, tinham processos de educação muito peculiares, isto é, dentro de suas tradições, práticas e costumes culturais que eram tidos como metodologias de transmissão dos conhecimentos e de saberes para os mais jovens. 


\section{HEGEMONIA DO ENSINO SUPERIOR: PERSPECTIVA REGIONAL BRASILEIRA}

Tendo como referência o debate sobre a distribuição das universidades no território brasileiro, verifica-se que existe uma espacialização desigual. Considerando as regiões que constituem a unidade federativa do Brasil, de certa forma algumas possuem forças hegemônicas em relação a outras. A exemplo disso, é a região Sudeste que detém uma infraestrutura privilegiada em relação a oferta de bens e serviços, como também um amplo número de Instituições de Ensino Superior. Esse fator referente a expansão de universidades no Sudeste, se dar pela grande concentração de IES privadas. Neste sentido, analisando as demais regiões brasileiras, não é notório essa percepção de expansão identificada no Sudeste. Desta forma, a referida região pode ser destacada por sua hegemonia, quando se considera a quantidade de IES territorializadas. Essa perspectiva é destacada na citação abaixo:

\footnotetext{
Quando esboçamos um quadro geral da presença de IES no Brasil, percebemos a desigualdade na distribuição das mesmas pelo território nacional. O uso seletivo do território pelos agentes hegemônicos elege apenas subespaços para participar ativamente dos circuitos produtivos. Dessa forma, ainda encontramos grandes vazios relativos à distribuição de IES no território brasileiro, especialmente nas regiões Norte e Centro-Oeste. Percebemos então, que a expansão territorial das IES está diretamente vinculada à concentração do meio técnico-científico-informacional (FREIRE; HOLANDA, 2016, p. 07).
}

Segundo os autores acima, pode-se entender que no território brasileiro existem desigualdades quando se analisa a distribuições das IES, em especial nas regiões Norte e Centro-Oeste. Quando comparada a região Norte, pode-se verificar que há uma disparidade com relação a demografia e infraestrutura, em razão disso as instituições de Ensino Superior tendem a se expandir em locais desenvolvidos tecnologicamente com expressividade no que se refere ao aspecto demográfico e tecnológico. Freire e Holanda (2018), corroboram com essa discussão e destacam que a região Norte é a que possui o menor número de IES.

No mapa abaixo, pode-se observar a distribuição das Instituições de Ensino Superior nas regiões do Brasil no ano de 2018, ao analisar o referido material, 
nota-se que a região Sudeste possui um quantitativo de 1.126 IES. Quando se analisa a região Norte, percebe-se que possui 173 instituições, quantitativo bem inferior ao Sudeste. Isso pode ser reflexo da ocupação territorial, no que diz respeito a quantidade populacional e, a densidade demográfica de cada região. As demais regiões apresentam um número de IES ainda de certo modo insuficiente para atender a demanda total local.

Tendo como base essas afirmações em relação as regiões e, a ocupação do território brasileiro, segundo o IBGE (2010) a população do estado de São Paulo, obtinha um quantitativo de cerca de 41.252.160 de habitantes, em comparação com o estado do Amazonas, localizado na região Norte, obtinha um total de 3.480.937 habitantes, pode-se analisar as desigualdades em relação a ocupação e desenvolvimento tecnológico, científico e educacional nas regiões brasileiras.

O contexto traçado acima pode ser melhor analisado a partir da leitura do mapa 01, em que é destacado a espacialização de IES, tendo como referência dados do INEP (2018).

\section{Mapa 01- Número de IES no território brasileiro.}

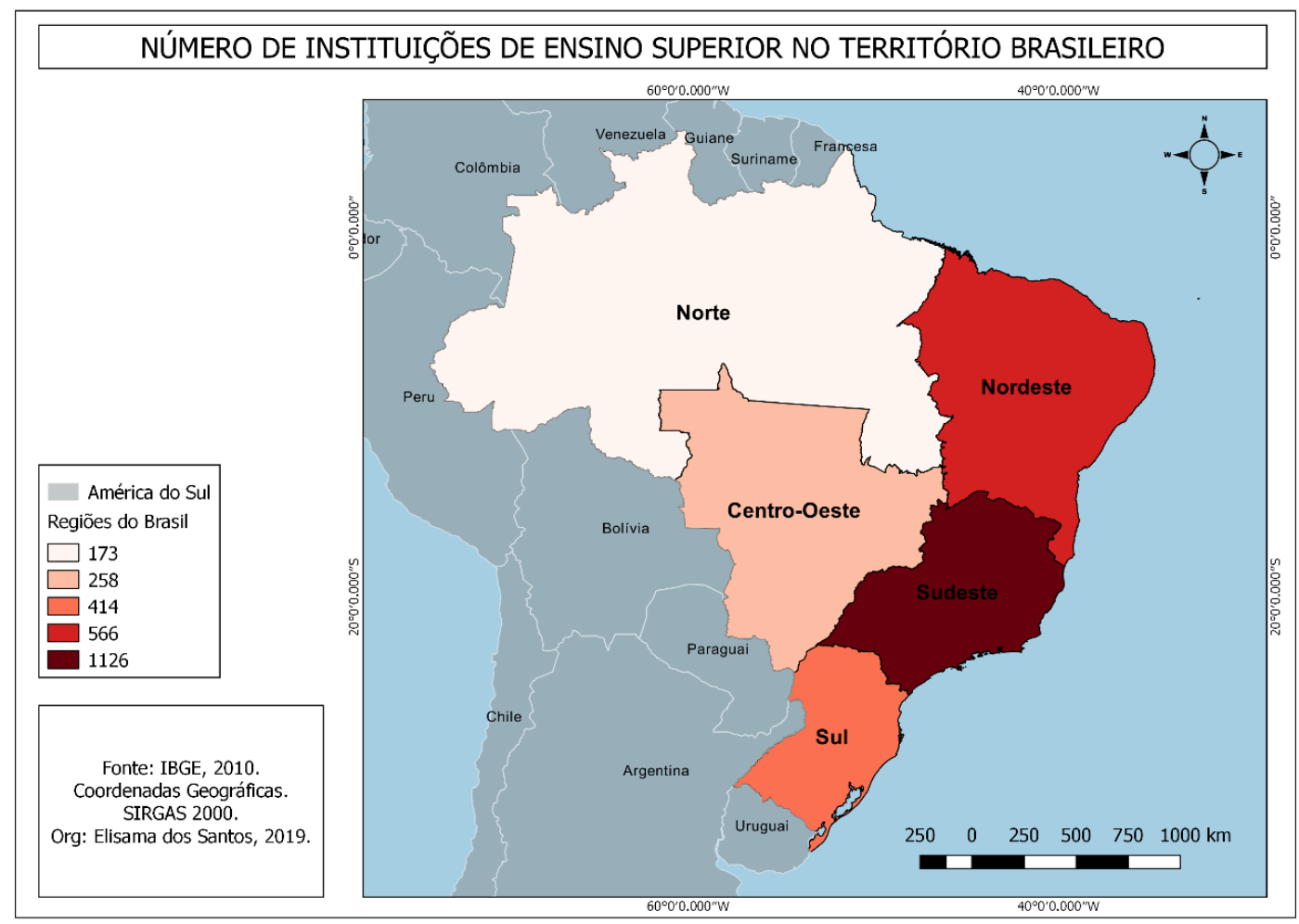

Org.: Elisama Santos, 2019. 


\section{CIDADE DE BARREIRAS: POLO DE ENSINO SUPERIOR}

A cidade de Barreiras está localizada na Mesorregião do Extremo Oeste Baiano é considerada cidade média, segundo o Instituto Brasileiro de Geografia e Estatística -IBGE. Atualmente a cidade obtém um número de 137.427 habitantes, conforme dados do Censo Demográfico do IBGE (2010), porém a população estimada para 2018 está em torno de 153.831 habitantes, segundo informações do órgão já mencionado acima. Barreiras é considerada a maior cidade do Oeste Baiano em relação aos aspectos demográficos. No que diz respeito a população urbana e população rural, conforme o Censo Demográfico de 2010, o município possuía 123.734 habitantes residindo na zona urbana e 13.694 na zona rural.

Nesse contexto, destaca-se a cidade de Barreiras, enquanto polo de referência em Ensino Superior, Ciência e Tecnologia. A referida cidade se consolida enquanto um polo, pois concentra uma série de IES, incluindo instituições públicas e privadas, fazendo com que este recorte regional se torne um atrativo para jovens de várias partes do Brasil, que buscam um diploma em nível superior em cursos nessas instituições. Os impactos sociais, econômicos, políticos e culturais são imensuráveis, pois a demanda por estas universidades aquece a economia local e, aos poucos vai reconfigurando e destacando o papel dessa região no cenário nacional e internacional. Tratar-se-á essa discussão com maiores detalhes mais adiante.

Realizada essa breve introdução de aspectos gerais, o debate daqui por diante terá como recorte espacial e temporal o estado da Bahia com direcionamento das discussões para a região Oeste, tendo como norte geográfico de análise de dados o espaçamento entre 2014 a 2018. Nesse sentido, tratar-se-á o embasamento com foco regional, ou melhor, mais especificamente tomando a cidade de Barreiras como um Polo de Ensino Superior na região Oeste da Bahia, como dito anteriormente. 
A delimitação desse recorte se faz necessária para a melhor compreensão da importância das IES públicas e privadas no desenvolvimento regional e, na formação de profissionais em várias áreas do conhecimento científico, somando a isto a dinamização da economia local e regional.

A seguir apresenta-se o mapa 02 de localização da referida cidade para situar o leitor sobre seu referencial geográfico e regional.

Mapa 02- Localização da cidade de Barreiras-BA.

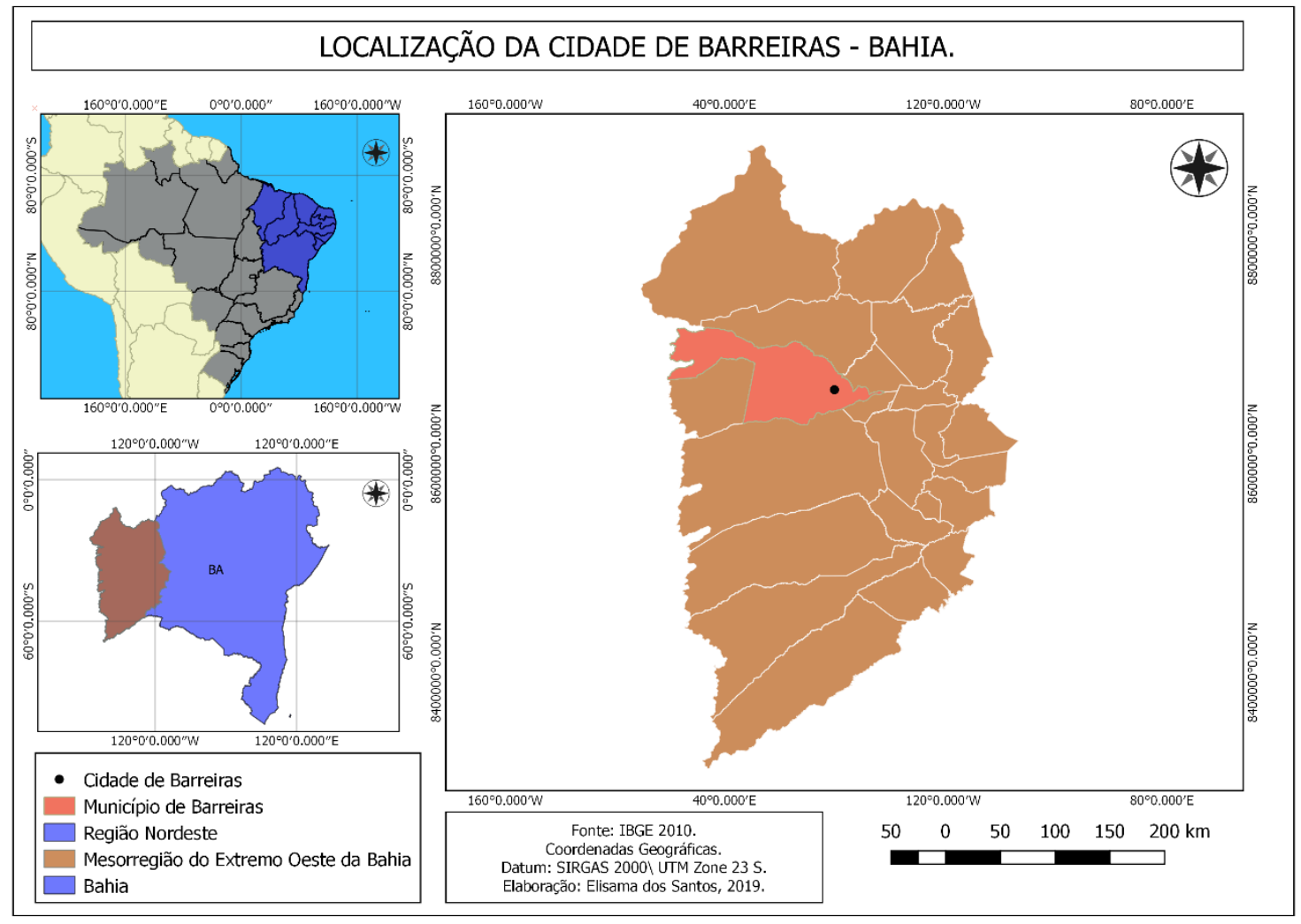

Org.: Elisama Santos, 2019.

\section{MÉTODO E METODOLOGIA}

Esta pesquisa teve como princípio o método dialético, esse procedimento é utilizado para a interpretação de fatos. Neste sentido, a dialética fornece possibilidades de compressão, fazendo com que haja um entendimento com 
relação aos aspectos sociais, que não podem ser assimilados desassociados do contexto, político, econômico, cultural e educacional. Nessa perspectiva, entendese que a dialética fornece subsídio para uma "interpretação dinâmica e totalizante da realidade" (GIL, 2008, p.14).

Para o desenvolvimento desta pesquisa foi necessário levantamento da literatura pertinente ao tema em exposição, nesse caso, foram consultados materiais bibliográficos como: livros, dissertações, teses, artigos científicos e bancos de dados disponíveis na internet e órgãos de pesquisa, assim como dados empíricos. Foi utilizado o programa Quantum GIS 2.14.16 para a elaboração de mapas qualitativo e quantitativo, tendo como base dados coletados no Instituto Nacional de Estudos e Pesquisas Educacionais Anísio Teixeira - INEP e Instituto Brasileiro de Geografia e Estatística - IBGE.

Nesse sentido, foi pertinente a utilização do software Google Earth Pro, tendo como objetivo principal coletar pontos de coordenadas em Universal Transversa de Mercator - UTM, para a posterior confecção de mapa de localização das IES espacializadas geograficamente na cidade de Barreiras e região Oeste da Bahia. Nessa perspectiva, para o enriquecimento da pesquisa após a depuração dos dados coletados em campo, foi elaborado gráficos no Microsoft Excel com o objetivo de facilitar a depuração e análise das informações, além disso, foi realizada atividade de campo em busca de dados em universidade Federal, Estadual, Privadas e Instituto Técnico Federal presente na cidade com foco dessa pesquisa.

É importante mencionar aqui que a visita técnica a essas instituições perfaz uma fase importante no desenvolvimento da pesquisa, pois proporciona a 
aquisição de dados a respeito do quantitativo de estudantes matriculados em cursos específicos: Área da Saúde: Medicina, Farmácia, Biologia e Nutrição; Área das Humanas: Direito, Geografia, Administração, Arquitetura e Bacharelado Interdisciplinar em Humanidades; Ciências Agrárias: Agronomia e Medicina Veterinária; Área das Ciências Exatas: Engenharia, Matemática e Bacharelado Interdisciplinar em Ciência e Tecnologia, no período de 2014 a 2018, como já descrito anteriormente.

Os cursos foram selecionados tendo como base o viés social e científico, e pela caracterização eminente de cursos superiores que possuem uma demanda quantitativa pela sociedade barreirense. A cidade possui um número expressivo de IES, obtendo um total de 41 Instituições de Ensino Superior no ano de 2019, deste modo foram selecionadas apenas sete para o seguimento da pesquisa sendo elas: Universidade Federal do Oeste da Bahia - UFOB (mais os campus territorializado nas cidades de: Luís Eduardo Magalhães, Bom Jesus da Lapa e Barra); Instituto Federal da Bahia - IFBA, (campus Barreiras); Universidade do Estado da Bahia - UNEB, (campus IX); Faculdade São Francisco de Barreiras FASB; Faculdade D. Pedro II; Faculdade Regional da Bahia - UNIRB e Universidade Norte do Paraná - UNOPAR.

A natureza metodológica utilizada para o andamento da pesquisa perfaz a metodologia quali-quantitativa, tendo em vista que é realizado uma análise de dados numéricos e também complementada com reflexões qualitativas, sendo embasadas e correlacionada ao referido tema, possibilitando interfaces entre o qualitativo e o quantitativo. A seguir apresenta-se o mapa 03 de localização das Instituições de Ensino Superior na cidade de Barreiras. 
Mapa 03. Localização das Instituições de Ensino Superior em Barreiras.

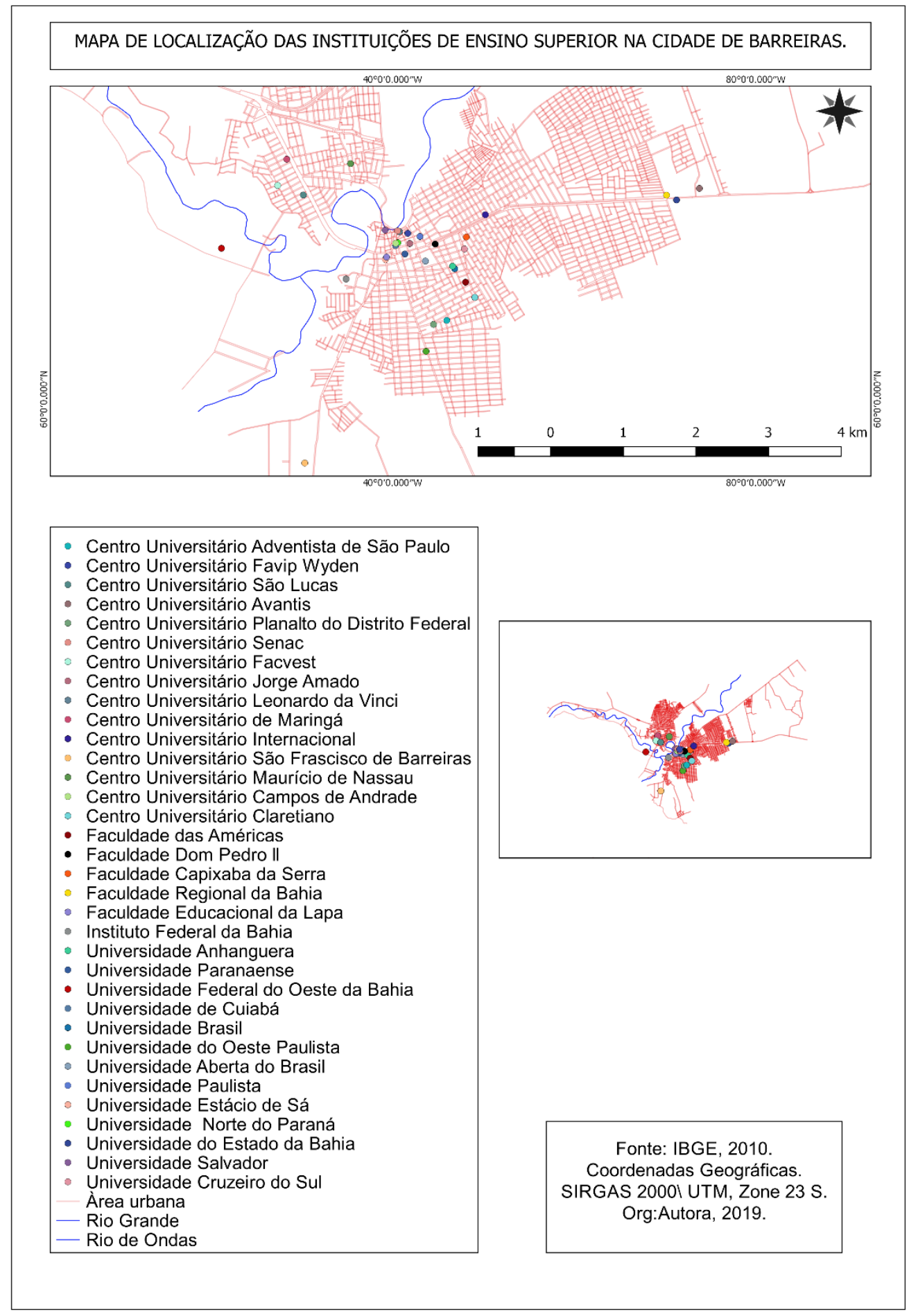

Org.: Elisama Santos, 2019.

\section{RESULTADOS E DISCUSSÕES}

\section{Compreender o significado da territorialização das já mencionadas} universidades na cidade de Barreiras, é essencial para a percepção e análise 
crítica em relação a essas Instituições de Ensino Superior, tendo como pilar o Ensino, Pesquisa e Extensão, isto é, o tripé das universidades públicas. Esses fatores entrelaçados perfazem o norte, ou seja, projeta um direcionamento para a produção de conhecimento científico de forma interligada tencionando para fora dos "muros" acadêmicos.

As IES que possuem curso de medicina na cidade de Barreiras detêm de um número significativo de estudantes matriculados. É bom ressaltar que embora este curso seja considerado um dos mais procurados, atualmente o mesmo encontra-se bastante mesclado em relação ao perfil socioeconômico de seus estudantes, pois as políticas de incentivo educacionais como: crédito educativo, cotas sociais e o próprio PROUNI possibilitou a entrada de estudantes advindos de outras classes sociais. Abaixo apresenta-se o gráfico 01 com o quantitativo de estudantes matriculados em curso de medicina nas IES em Barreiras.

Gráfico 01- Quantitativo de Estudantes Matriculados em Curso de Medicina na FASB e UFOB na Cidade de Barreiras para o Ano de 2018.

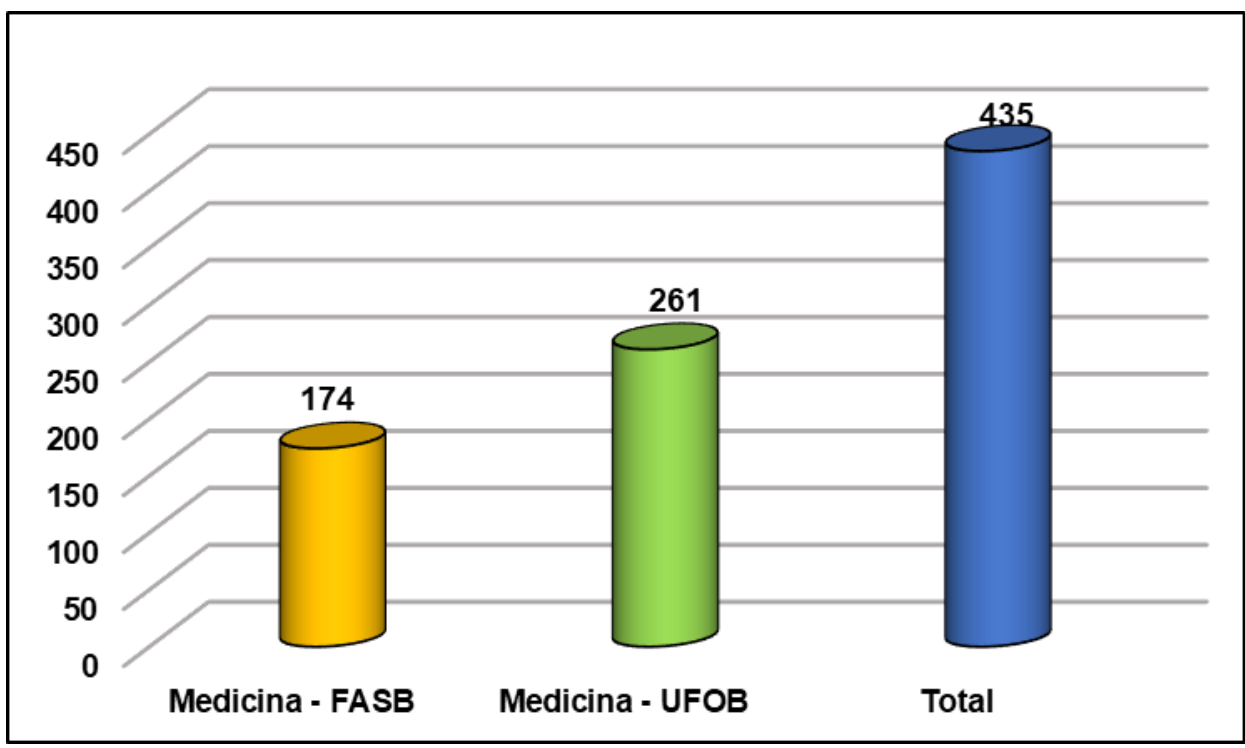

Fonte: UFOB e FASB. Pesquisa de campo, 2018. Org.: Elisama Santos, 2019.

Ao analisar o gráfico 01, percebe- se que este curso possui uma demanda significativa na cidade, essa perspectiva pode ser confirmada a partir da 
apreciação dos dados apresentados. A FASB possui 174 estudantes matriculados no curso de medicina, sendo que 14 são bolsistas do PROUNI.

É importante destacar que as políticas públicas referentes a inclusão e acesso ao Ensino Superior tem feito com que pessoas de camadas sociais mais vulneráveis socialmente possam frequentar o curso de medicina com o apoio do Programa Universidades para Todos - PROUNI e, a partir de Universidades Estaduais e Federais. Na cidade de Barreiras, o curso de medicina é encontrado em duas Instituições, sendo elas a Faculdade São Francisco de Barreiras-FASB e Universidade Federal do Oeste da Bahia-UFOB. Em 1999 a Faculdade São Francisco de Barreiras iniciou suas atividades educacionais na cidade. Esta instituição há 20 anos está implantada e oferecendo cursos para a profissionalização e formação dos barreirenses. Neste sentido, segue fotos da referida Instituição.

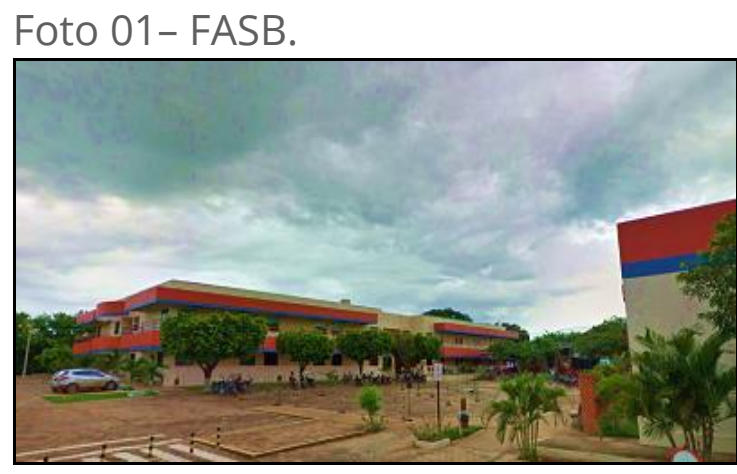

Fonte: Acervo da autora, 2019.

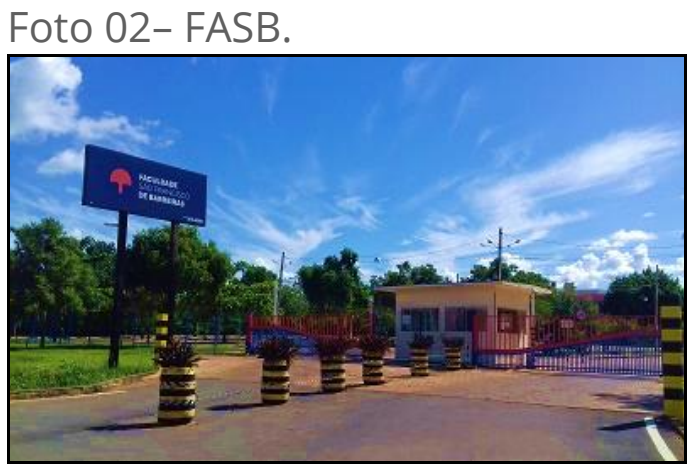

Fonte: Acervo da autora, 2019.

Uma breve pausa na discussão referencial para destacar ao leitor que desde o período colonial a formação referente a medicina foi implantada, juntamente com outros cursos destinados a classe aristocrática e seus sucessores, é importante colocar em ênfase que este curso é antigo e possui raízes na sociedade, juntamente com a formação das IES.

O curso de matemática ofertado em IES na cidade é encontrado em instituições, sendo públicas e privadas. Vale ressaltar que as matrículas no referido curso, são mais expressivas nas instituições públicas. Ao analisar esse detalhe é notório o entendimento com relação a importância de IES Estadual e 
Federal na cidade, pois é por meio das instituições públicas, que a população menos favorecida tem oportunidade de usufruir de um ensino gratuito e de qualidade. Tendo como princípio a modalidade de ampla concorrência e a lei de cotas (raça, vulnerabilidade socioeconômica, estudantes oriundos da rede pública de ensino, cotas regionais) possibilitando o estudante da rede pública adentrar no curso de Matemática nas universidades públicas em Barreiras. Para maior embasamento a respeito deste debate segue abaixo o quantitativo de estudantes matriculados no referido curso.

Gráfico 02- Quantitativo de Estudantes Matriculados em Curso de Matemática na UNOPAR, UFOB, IFBA, UNEB na Cidade de Barreiras Para o Ano de 2018.

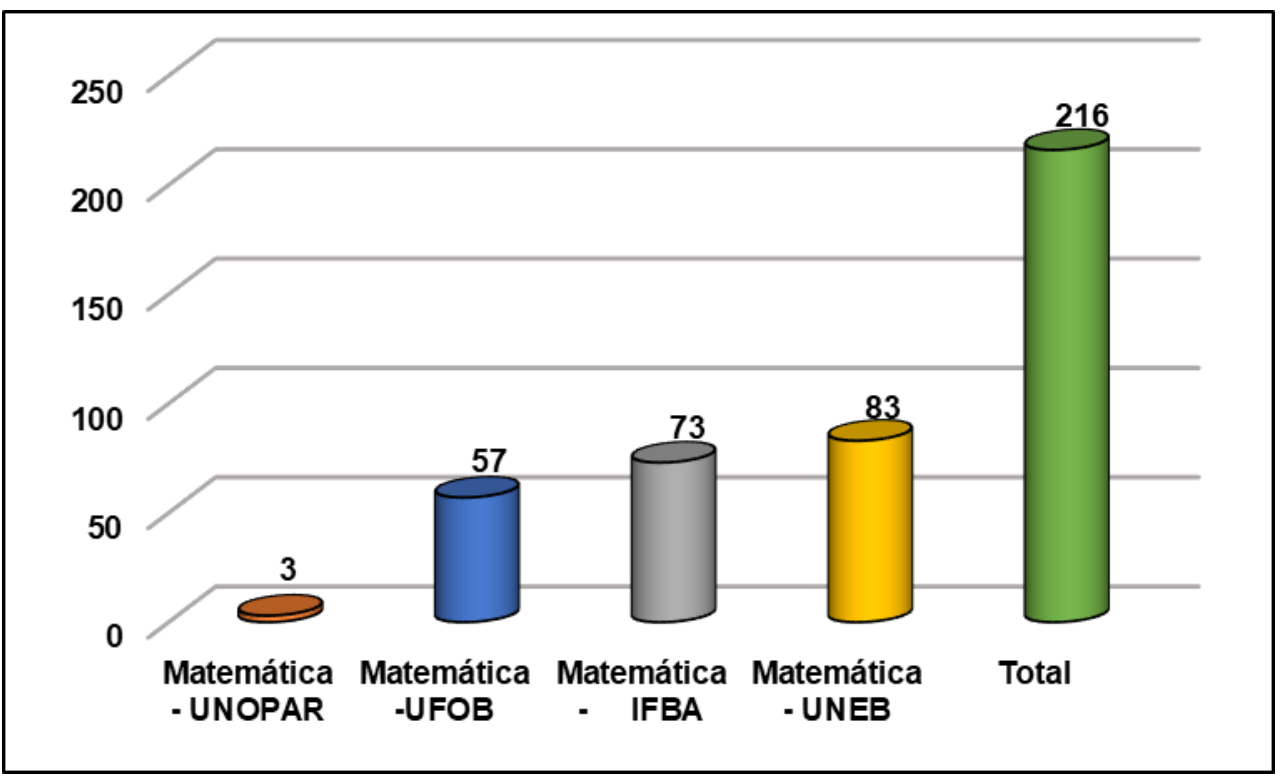

Fonte: UNOPAR, IFBA, UFOB e UNEB. Pesquisa de campo, 2018. Org.: Elisama Santos, 2019.

Com relação aos dados referente ao quantitativo de estudantes matriculados em ambas instituições, é importante destacar que um dos fatores condicionantes a Universidade do Estado da Bahia obter um número maior de matrículas no curso em debate, pode estar correlacionado ao fato dessa instituição ter sido implantada em Barreiras a décadas.

Carvalho (2008) enfatiza que a implantação da Universidade do Estado da Bahia na cidade de Barreiras, coincidiu com a chegada do agronegócio no Oeste 
Baiano na década de 1970. A UNEB foi umas das universidades pioneiras quando se analisa o Ensino Superior na região Oeste da Bahia, sendo a primeira universidade pública no município, e isso pode ser um fator condicionante ao maior número de estudantes matriculados no curso de matemática. Abaixo pode ser observado fotos da faixada da instituição mencionada anteriormente. A mesma encontra-se localizada na saída leste da cidade de Barreiras, não muito distante do centro comercial.

Foto 03- UNEB.

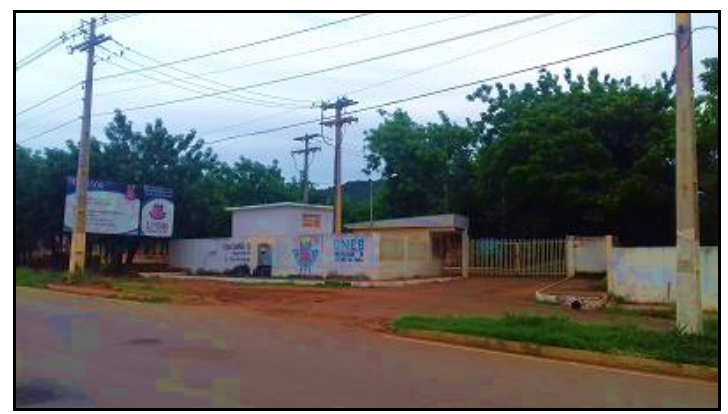

Fonte: Acervo da autora, 2019.
Foto 04- UNEB.

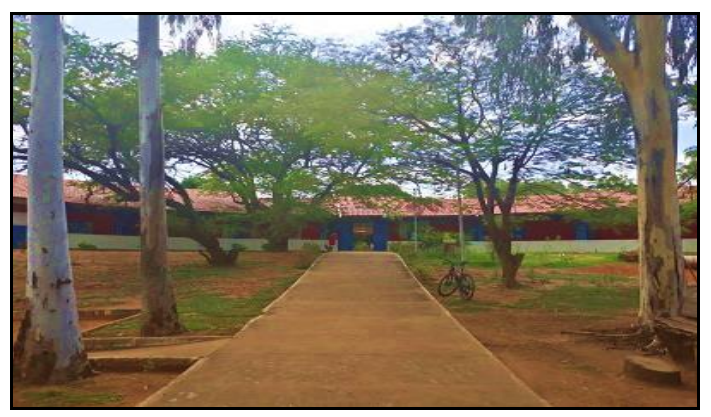

Fonte: Acervo da autora, 2019.

Dando continuidade à análise passar-se-á agora a discorrer sobre as matrículas em cursos de Ciências Biológicas, Uliana (2012) evidencia que o referido curso foi implantado no Brasil na Universidade de São Paulo - USP em 1934, primeiramente denominado de História Natural. O curso é pertencente a ciências da saúde, estando inserido no currículo escolar nas instituições de ensino na Educação Básica, no Ensino Fundamental e Ensino Médio.

Com base nos dados apresentados no gráfico abaixo pode-se aferir que a UNEB possui um quantitativo de 114 estudantes, ficando muito próximo do número de matriculados no mesmo curso na instituição UFOB a qual apresenta um quantitativo de 129 para o ano de 2018. Neste sentido, a quantidade de estudantes nos cursos de Bacharéis e Licenciatura em Biologia da Universidade Federal do Oeste da Bahia - UFOB se distinguem da seguinte maneira: 65 
vinculados na habilitação Bacharelado e 64 na habilitação Licenciatura. Já na Universidade do Estado da Bahia - UNEB, possui apenas o curso na modalidade de Licenciatura, com um total de 114 matriculados.

Quando se analisa o curso na cidade em tela observa-se que o mesmo possui uma grande procura, essa perspectiva pode ser comprovada no gráfico 03.

Gráfico 03- Quantitativo de Estudantes Matriculados em Curso de Biologia na UNEB e UFOB na Cidade de Barreiras Para o Ano de2018.

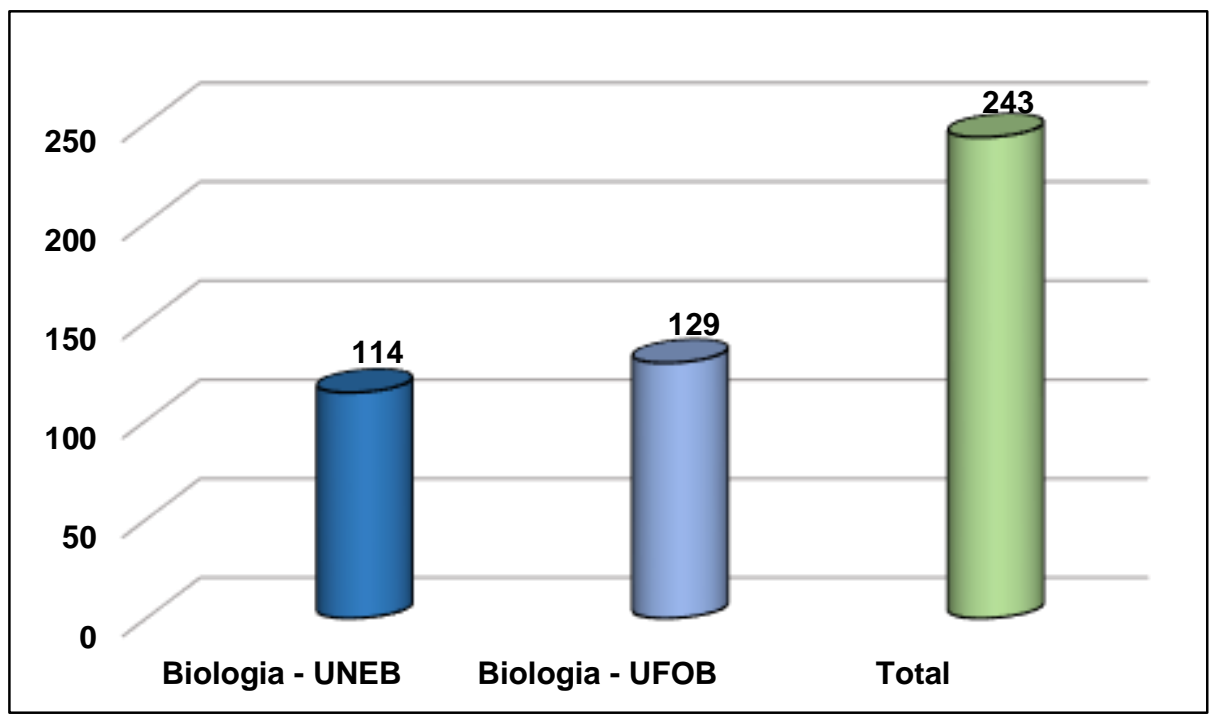

Fonte: UNEB e UFOB. Pesquisa de campo, 2018. Org.: Elisama Santos, 2019.

As Instituições analisadas, sendo elas públicas e privadas, verifica-se que nas IES públicas o número de cursos presenciais destinados para a formação de professores é consideravelmente superior em comparação com as privadas, pois nessas últimas, a grande maioria dos cursos são na modalidade Bacharel. A exemplo o curso de direito, que é encontrado em quatro IES na cidade, sendo uma pública e três privadas, e possui ampla demanda de estudantes 
matriculados. Essa afirmação pode ser constatada através de dados coletados em campo, posteriormente depurados e transformados em gráfico para melhor análise do leitor.

Gráfico 04 - Quantitativo de Estudantes Matriculados em Curso de Direito na UFOB, FASB, e UNIDOM em Barreiras para o Ano de 2018.

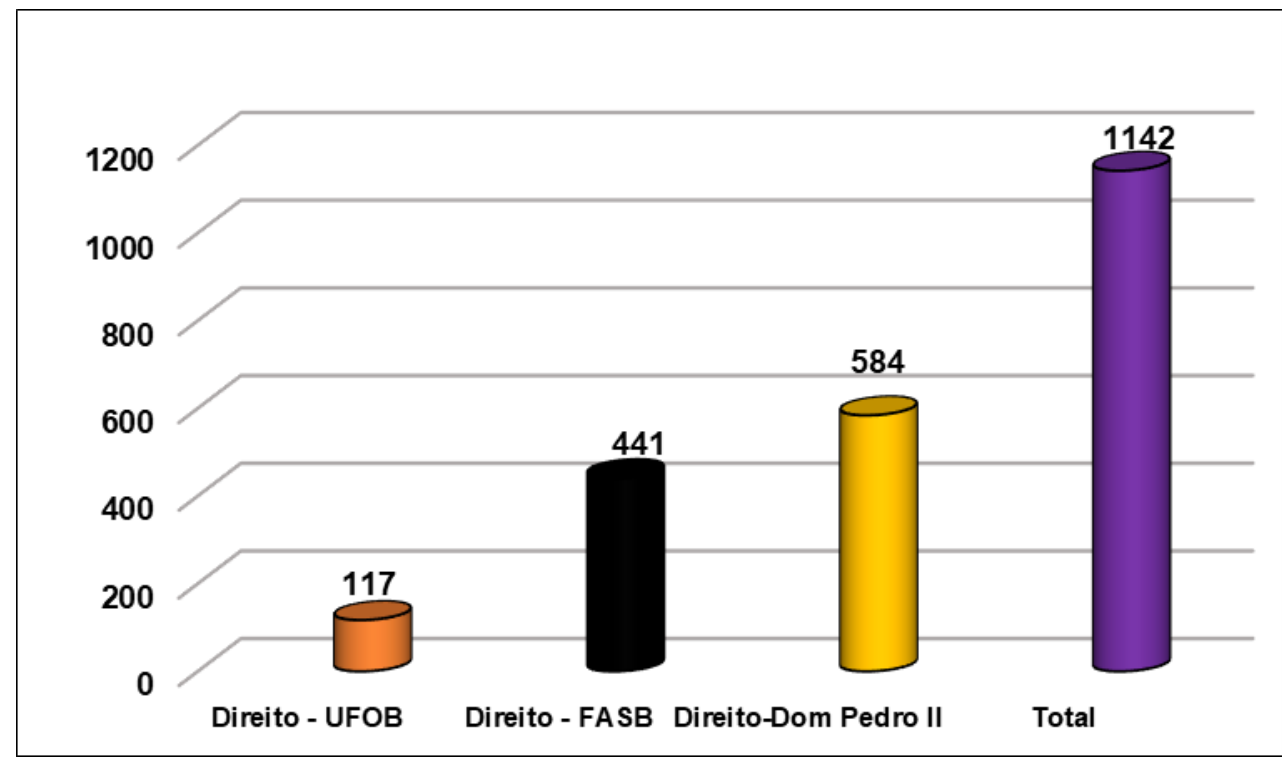

Fonte: UFOB, FASB e Faculdade D. Pedro II. Pesquisa de campo, 2018 Org.: Elisama Santos, 2019.

Todavia, é importante destacar que a demanda pode ser resultante (FASB e Faculdade D. Pedro II) da implantação dessas IES, pois foram em período anterior a UFOB, tendo em vista que a Universidade Federal do Oeste da Bahia é recente, mas que por sua vez, oferece uma grande quantidade de cursos presenciais, quando comparada com as demais IES existentes na cidade. Em relação ao curso de graduação em Administração, pode ser considerado um dos mais requisitados, pois possui um quantitativo de 36 estudantes na FASB, 120 estudantes UFOB e 395 na Faculdade D. Pedro II, matriculados, perfazendo um total de 650 vinculados, dados que podem ser visualizados no gráfico abaixo. 
Gráfico 05- Quantitativo de Estudantes Matriculados em Curso de Administração na FASB, UFOB, UNOPAR e UNIDOM, na Cidade de Barreiras Para o Ano de 2018.

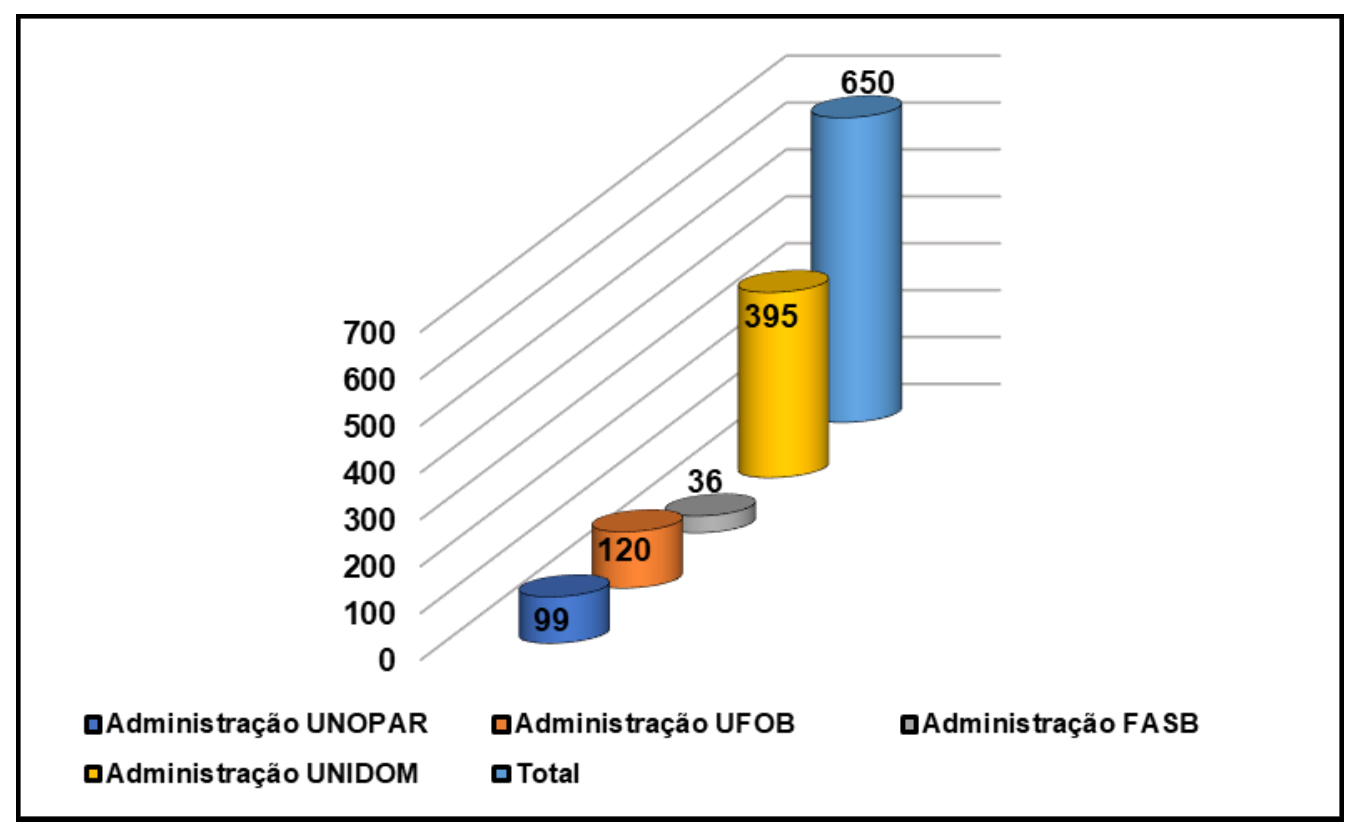

Fonte: UNOPAR, FASB, UFOB e Faculdade D. Pedro II. Pesquisa de campo, 2018. Org.: Elisama Santos, 2019.

Com relação ao curso de Administração, a rede privada possui maiores números de matriculados. Neste sentido, pode-se destacar que detém esse quantitativo, pois nas universidades privadas a grande maioria dos cursos são noturnos, como o curso de Administração na Faculdade D. Pedro II e na UNOPAR. Isso possibilita uma dinâmica em relação a matrícula e a acessibilidade com relação a classe trabalhadora, que oferece sua força de trabalho durante o período diurno e estuda no noturno, a exemplo de muitos estudantes matriculados na Faculdade D. Pedro II, a qual apresenta o maior quantitativo de matrículas em curso de Bacharel em Direito.

Com o crescimento que Barreiras obteve na década de 90 até os dias atuais, as Instituições Superiores Privadas vêm se territorializando na região, e em especial na cidade de Barreiras. Atualmente a quantidade de IES privadas excedem as públicas. Neste sentido, a Faculdade D. Pedro II contempla uma grande quantidade de estudantes, que visam uma formação para o mercado de 
trabalho. Para uma maior contextualização segue fotos da referida instituição em debate.

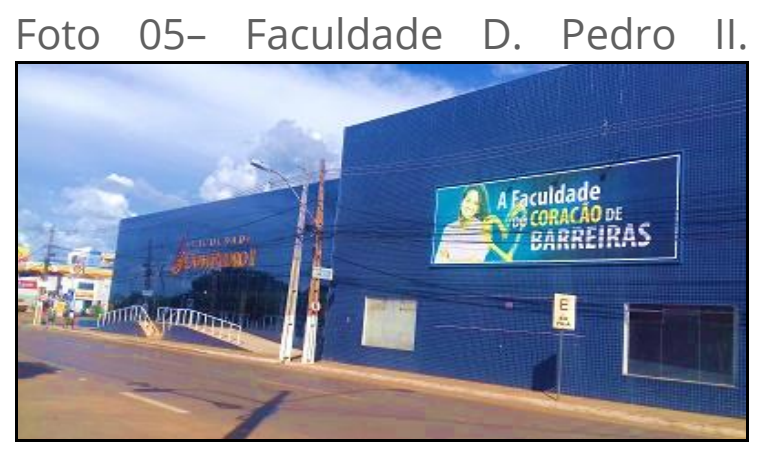

Fonte: Acervo da autora, 2019.

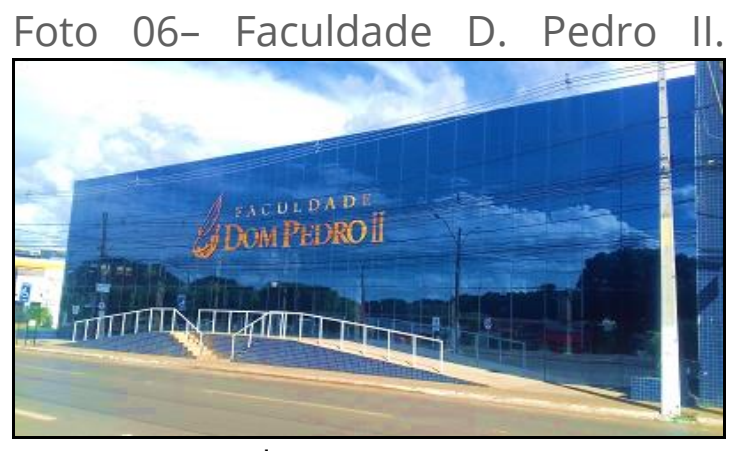

Fonte: Acervo da autora, 2019.

É importante destacar que as IES que possuem curso noturnos, interfere assiduamente na Pesquisa, tendo em vista que a universidade que tem cursos integrais, possibilita o exercício no que se refere à Pesquisa e Extensão. É importante colocar em ênfase que existem exceções, e não se pode generalizar. Com relação ao curso de Agronomia presente na cidade de Barreiras, o referido foi encontrado em duas instituições: FASB e UNEB. Na UFOB (campus Barra) possui um quantitativo de 162 estudantes, na FASB, 191, e na UNEB 214, somando um total de 567 matriculados.

Para melhor compressão, segue o gráfico 06 que destaca o que foi discutido acima. A partir da análise dos referidos dados ver-se que a Universidade do Estado da Bahia possui um quantitativo maior, esse fato pode ser relacionado a questão da implantação da universidade, pois é considerada como pioneira em Barreiras. O curso de Agronomia da UFOB, está territorializado em Barra, cidade a qual se situa a $343 \mathrm{Km}$ de Barreiras. O curso de Agronomia no Oeste Bahia é extremamente relevante, a região está localizada na fronteira agrícola MATOPIBA (Maranhão, Tocantins, Piauí e Bahia), que por sua vez, tem se destacado na produção de grãos para exportação. O referido curso, detém uma demanda expressiva, sendo que este pode influenciar em pesquisas em relação à economia de exportação e produção de commodities. 
Gráfico 06- Quantitativo de Estudantes Matriculados em Curso de Agronomia na UFOB, FASB e UNEB na Cidade de Barreiras Para o Ano de 2018.

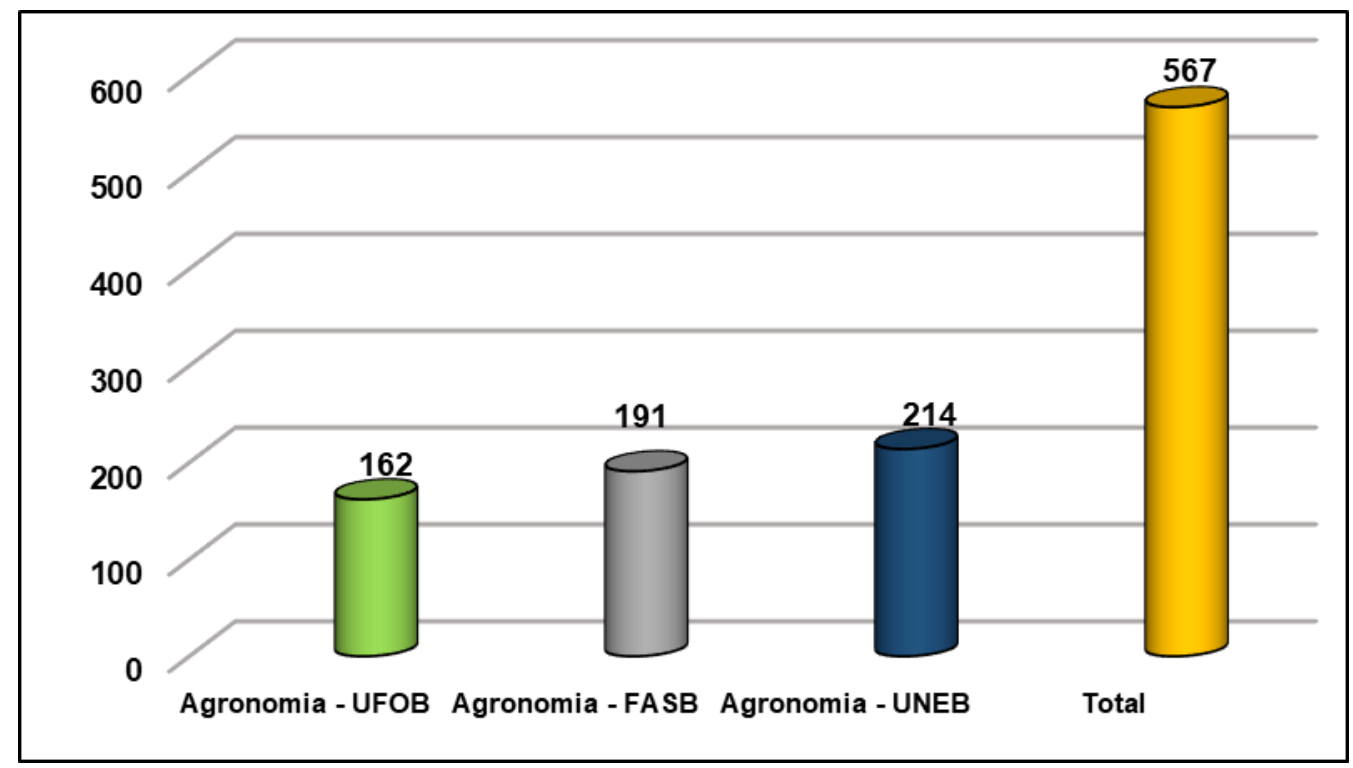

Fonte: UFOB, FASB e UNEB. Pesquisa de campo, 2018. Org.: Elisama Santos, 2019.

A Faculdade Regional da Bahia - UNIRB, foi implantada na cidade de Barreiras, disponibilizando vários cursos, sendo em sua grande maioria quase todos na modalidade Bacharel, ofertando apenas um curso na modalidade Licenciatura, sendo este o de Filosofia. Esta Instituição privada oferece cursos presenciais, e possui cursos que são em comum com a Universidade do Oeste da Bahia, um a ser citado é o de farmácia. Neste sentido, pode-se analisar fotos da UNIRB, na cidade de Barreiras:

Foto 07- UNIRB.

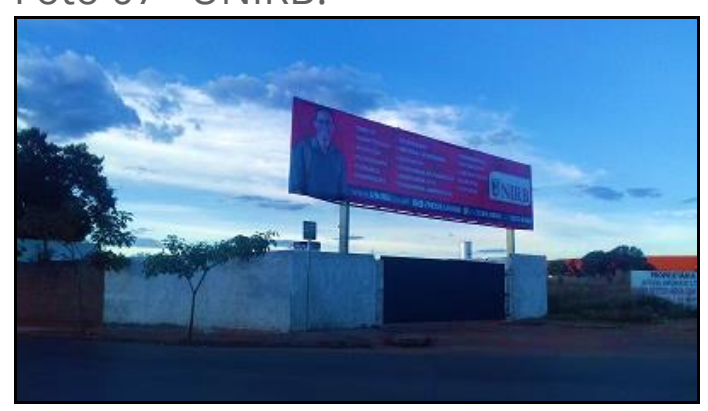

Fonte: Acervo da autora, 2019.
Foto 08- UNIRB.

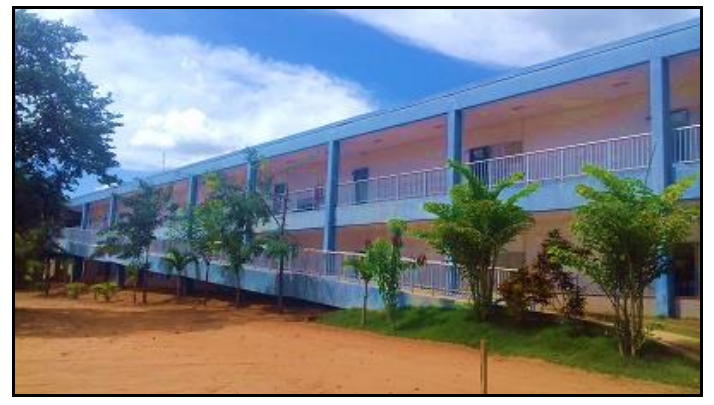

Fonte: Acervo da autora, 2019.

Com base nos dados do gráfico 07 abaixo, pode-se analisar a quantidade de estudantes matriculados no curso de farmácia na UNIRB e UFOB, sendo que a 
primeira é privada e a segunda pública. Nesta IES ver-se um quantitativo de 21 matriculados, já na UFOB, o quantitativo é superior, sendo um número de 162 estudantes.

Gráfico 07 - Quantitativo de Estudantes Matriculados em Curso de Farmácia na UNIRB e UFOB na Cidade de Barreiras Para o Ano de 2018.

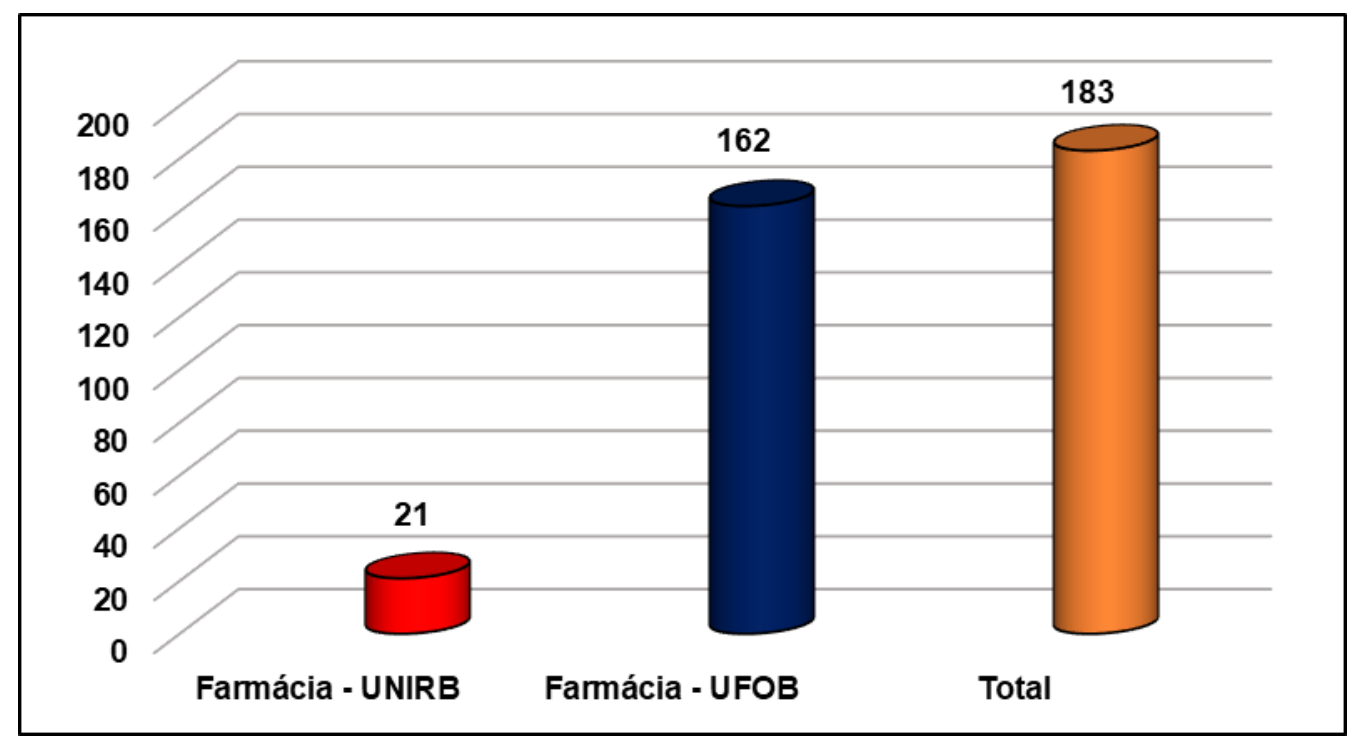

Fonte: UNIRB e UFOB. Pesquisa de campo, 2018. Org.: Elisama Santos, 2019.

A partir da análise do gráfico 07, ver-se que a UFOB é representativa na cidade, sendo caracterizada pela demanda de estudantes, não só de Barreiras, como também da mesorregião Extremo Oeste, e outros estados do Brasil.

Outro curso que é similar entre UNIRB e UFOB, é o de nutrição, a qual possui uma demanda mais expressiva quando compara ao curso de farmácia nas duas IES analisadas. Esses dados podem ser melhor contemplados no gráfico a seguir com o quantitativo de estudantes matriculados no curso de nutrição. Essa diferença pode ser induzida devido aos aspectos relacionados a infraestrutura física. A UFOB é destacada por oferecer uma estrutura privilegiada em relação aos laboratórios, biblioteca, restaurante universitário e corpo docente qualificado. Os dados referentes as duas IES podem ser analisados a seguir. 
É importante deixar em evidência que todos os cursos pesquisados vinculados a área da saúde, possuem uma grande demanda, havendo um quantitativo de matriculados significativos, essa questão pode ser visível nos dados abaixo. Levando em consideração os cursos de Licenciatura que possui um quantitativo ameno, e isso pode ser identificado também em instituições privadas na cidade. Entende-se que a profissão docente, tem sido pouca procurada, essa perspectiva pode ser confirmada a partir da análise dos dados do gráfico a seguir.

\section{Gráfico 08- Quantitativo de Estudantes Matriculados em Curso de Nutrição na}

UNIRB e UFOB na Cidade de Barreiras para o Ano de 2018.

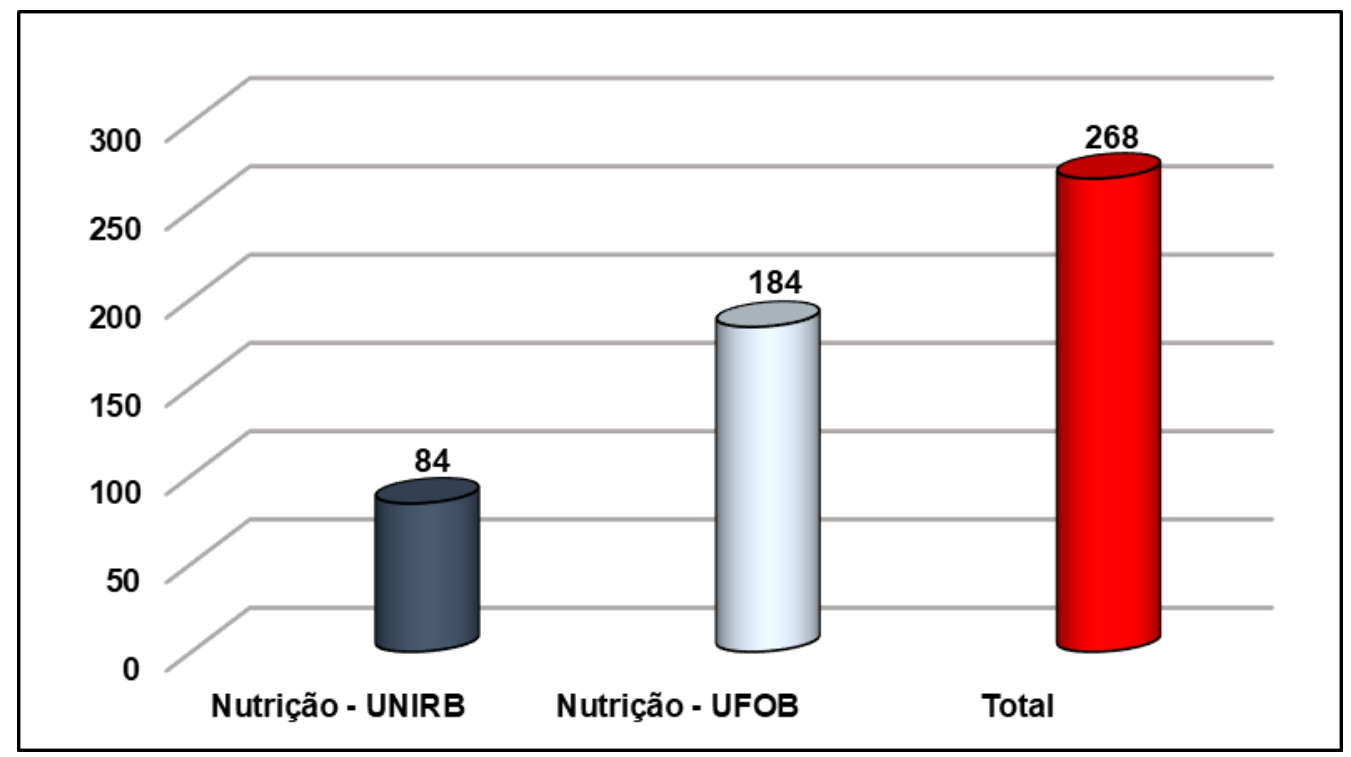

Fonte: UNIRB e UFOB. Pesquisa de campo, 2018. Org.: Elisama Santos, 2019.

Diferentemente com se analisa o curso de Engenharia, o qual possui uma grande demanda e oferta de vagas na Universidade Federal do Oeste da Bahia UFOB, não somente em Barreiras, como também em Bom Jesus da Lapa e Luís Eduardo Magalhães, são oferecidos cursos de Engenharias que não são ofertados 
nas demais IES da cidade de Barreiras como também na região. Esses dados podem ser analisados no gráfico 09 a seguir.

Gráfico 09- Quantitativo de Estudantes Matriculados nos Cursos de Engenharias nas IES: UFOB (Campus de Bom Jesus da Lapa, Barreiras e Luís Eduardo Magalhães), IFBA, UNIRB para o Ano de 2018.

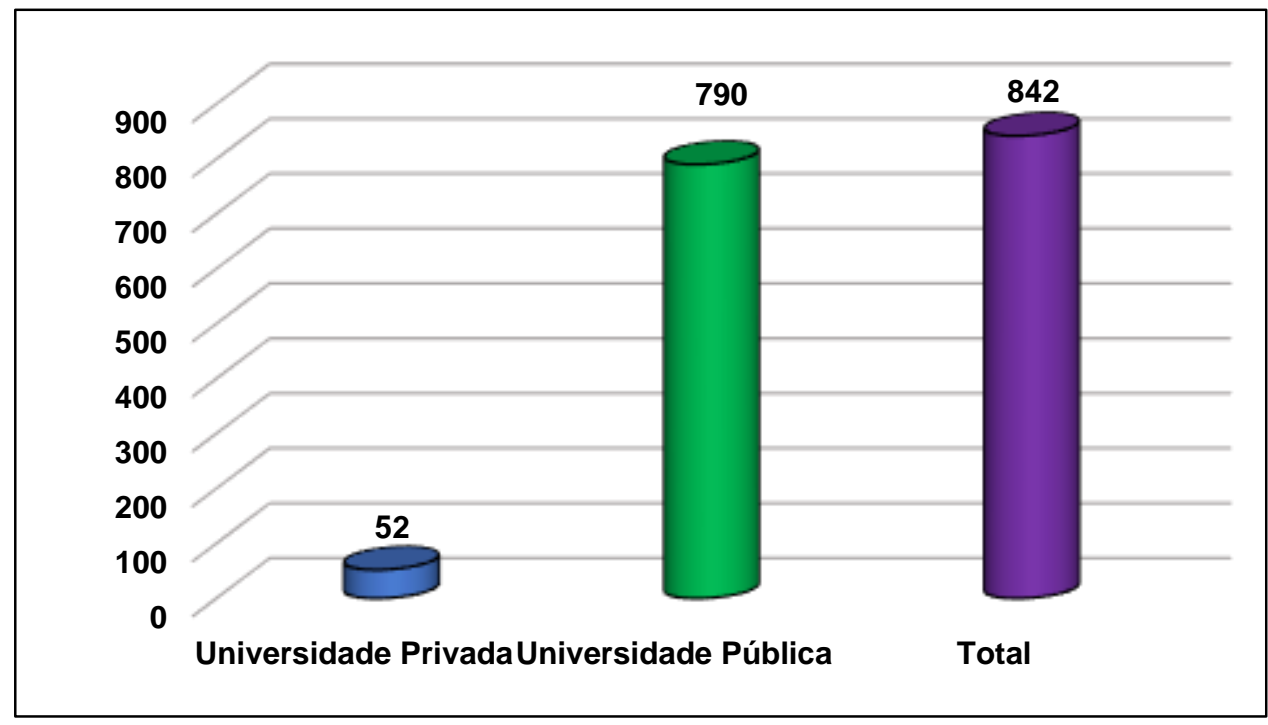

Fonte: IFBA, UFOB e UNIRB. Pesquisa de campo, 2018. Org.: Elisama Santos, 2019.

Com base no gráfico acima, pode-se analisar a expressividade de matriculados nos cursos de Engenharias. Sabe-se que este é frequente nas universidades públicas e privadas. Os dados referentes as engenharias, contemplam não só a cidade de Barreiras, como também nos munícipios em que a UFOB está interiorizada. No gráfico está a soma dos cursos de: Engenharia de Alimentos (IFBA), Engenharia Civil, Engenharia Elétrica, Engenharia de Produção (UFOB e UNIRB), Engenharia de Biotecnologia, Engenharia Mecânica, Engenharia Sanitária e Ambiental. Neste sentido, percebe-se a grande quantidade desses cursos, sendo um dos que possuem mais estudantes matriculados se comparados aos demais cursos selecionados para esta pesquisa. 
O Instituto Federal da Bahia - IFBA, teve início na cidade de Barreiras a partir da inauguração do CEFET- BA, em 1993, com início do ano letivo em 1994, essa instituição ofertava uma formação em nível de Ensino Médio simultaneamente ao nível técnico. No ano de 2013 iniciou-se o curso de Engenharia de Alimentos na Instituição, e posteriormente o curso de Arquitetura e Urbanismo em 2016. Foi quando o Instituto Federal da Bahia, passou a comtemplar estudantes destinados para a formação em nível superior. Neste sentido segue as fotos 09 e 10 da Instituição em debate.

\section{Foto 09- IFBA - Campus Barreiras. Foto 10- IFBA - Campus Barreiras.}

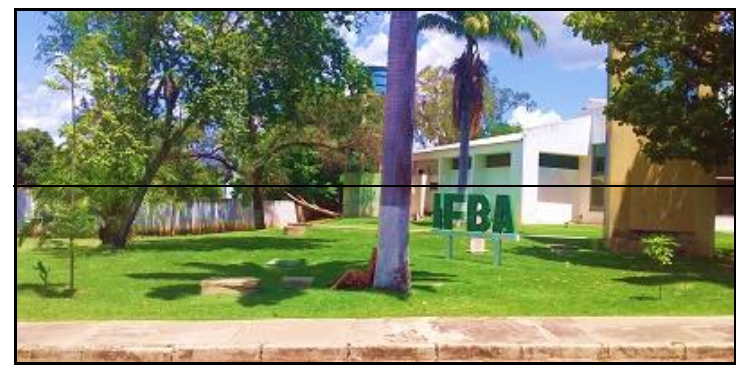

Fonte: Acervo da autora, 2019.

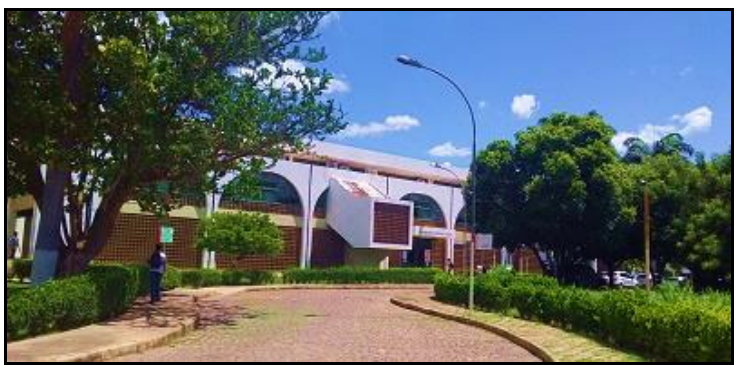

Fonte: Acervo da autora, 2019.

Tomando como referência os dados coletados em campo e após seu refinamento e depuração, pode-se realizar uma análise quantitativa e qualitativa com o objetivo de distinguir a quantidade de estudantes matriculados em cursos diferentes. A partir desses aspectos foi possível aferir uma análise crítica em relação as universidades visitadas. O curso de Medicina Veterinária, para ser implantado em determinada universidade, a mesma deve obter de uma estrutura adequada como: laboratórios, para que seja efetivado as aulas práticas. Diferentemente das Licenciaturas, que não precisam de grandes estruturas para a sua implantação. 
Tendo como base a discussão referente ao gráfico 10, ver-se que o curso de Medicina Veterinária é encontrado na UFOB, UNIRB e na UNEB. Na Universidade Federal do Oeste da Bahia (campus Barra) o quantitativo de estudantes é de 188, na UNEB é de 63 matriculados, e UNIRB com 71 estudantes.

\section{Gráfico 10- Quantitativo de Estudantes Matriculados em Curso de Medicina}

Veterinária na UNEB, UNIRB E UFOB na Cidade de Barreiras Para o Ano de 2018.

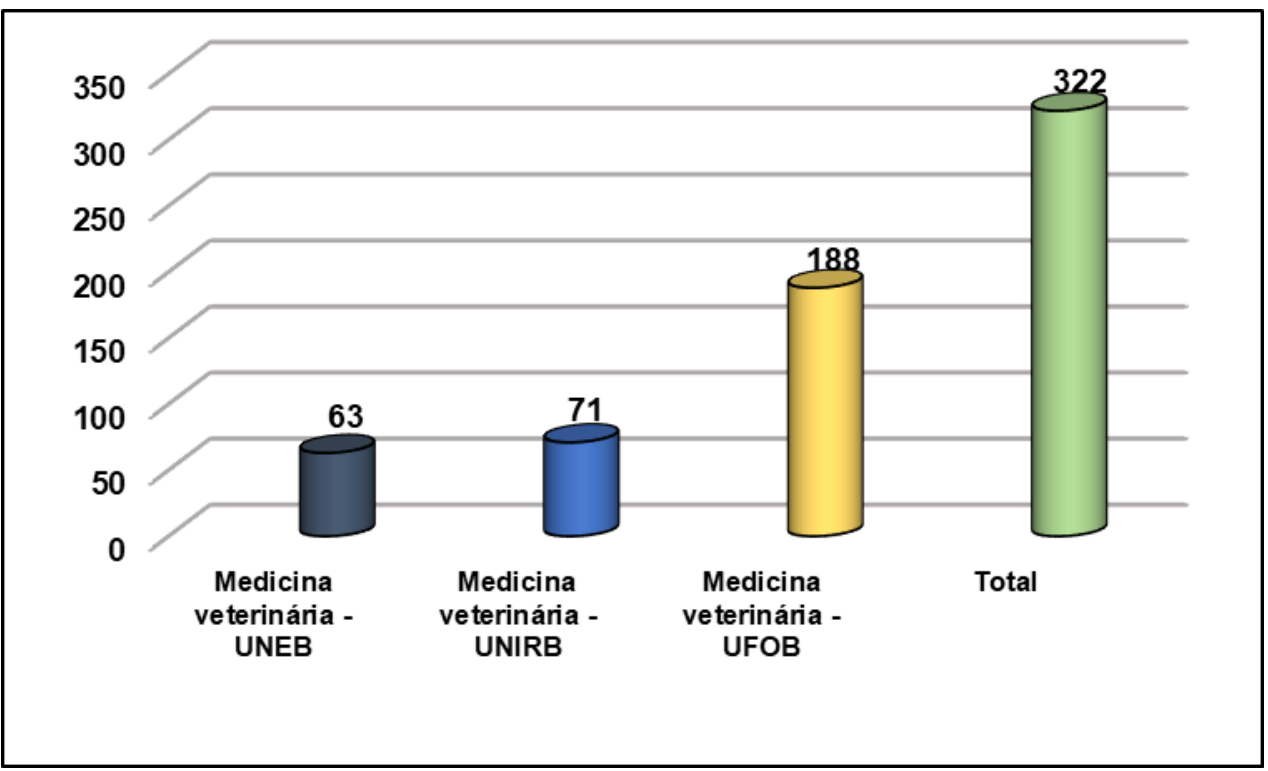

Fonte: UNEB, UNIRB e UFOB. Pesquisa de campo, 2018. Org.: Elisama Santos, 2019.

Os cursos vinculados a Ciências Humanas, como História, Geografia, ou seja, cursos destinados para a formação de profissionais para a área da educação, percebe-se uma discrepância com relação aos matriculados e, isso pode ser analisado de forma comparada com dados referentes ao curso de Medicina Veterinária e o de Geografia nas Instituições como: UNOPAR e UFOB, nessa perspectiva de matriculados, o curso de geografia na referida instituição possui pouca demanda. Esses dados podem ser analisados no gráfico 11 a seguir. 
Gráfico 11- Quantitativo de Estudantes Matriculados em Curso de Geografia na

UNOPAR e UFOB na Cidade de Barreiras Para o Ano de 2018.

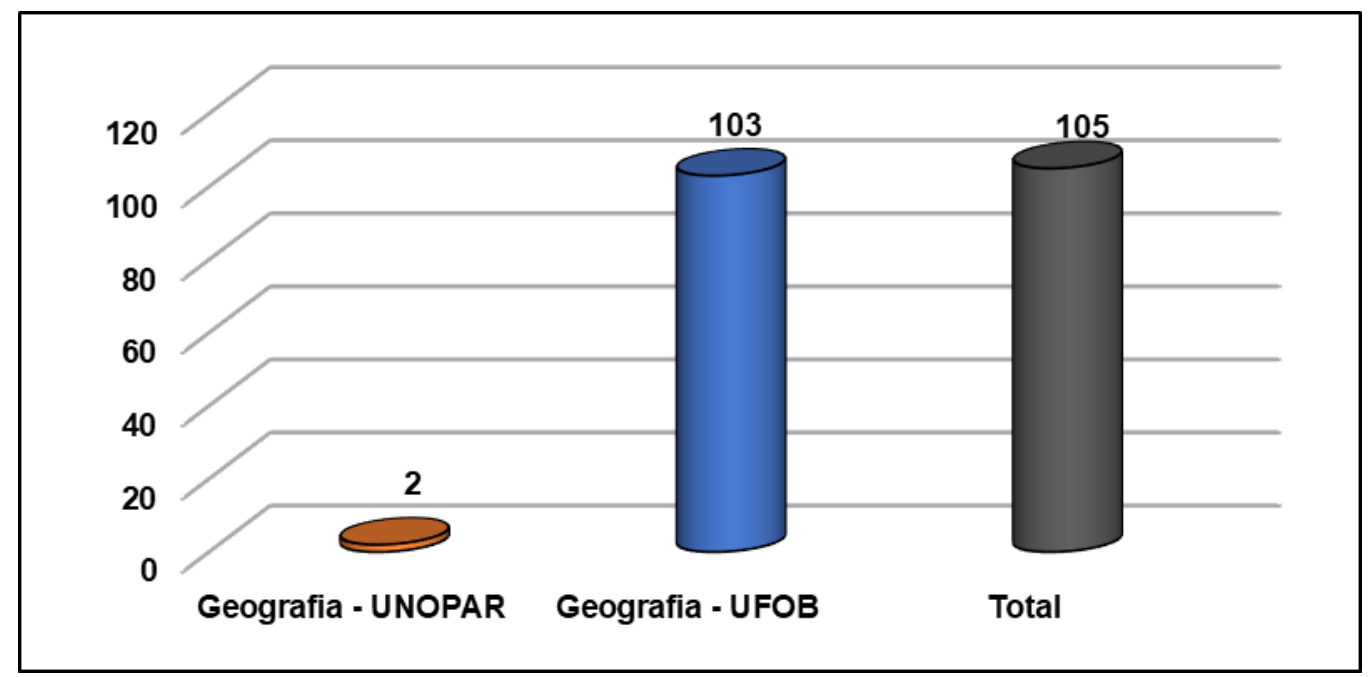

Fonte: UNOPAR e UFOB. Pesquisa de campo, 2018. Org.: Elisama Santos, 2019.

Com base nos dados se constata que o curso de geografia em modalidade presencial é encontrado somente na Universidade Federal do Oeste da Bahia UFOB, tendo em vista que na Universidade Norte do Paraná- UNOPAR, o curso é ofertado na modalidade semipresencial, tendo apenas dois estudantes matriculados. Se comparado ao curso presencial na UFOB, verifica-se uma disparidade muito grande em relação ao quantitativo de estudantes vinculados em ambas instituições. Seguem as fotos 11 e 12, da Instituição UNOPAR localizada no centro histórico de Barreiras.

\section{Foto 11- UNOPAR.}

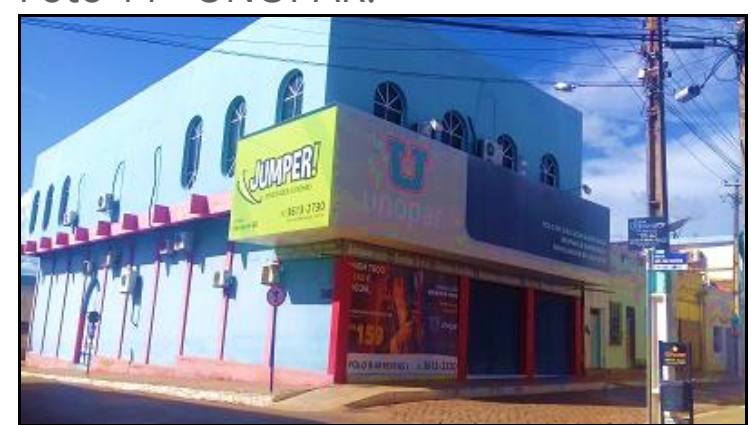

Fonte: Acervo da autora, 2019.
Foto 12- UNOPAR.

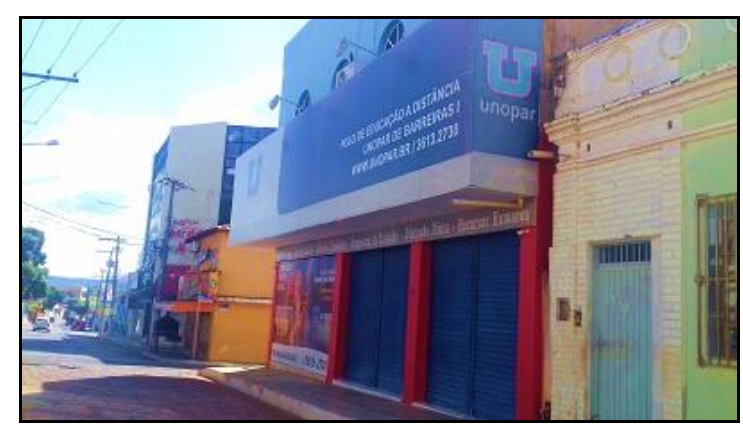

Fonte: Acervo da autora, 2019. 
A educação a distância não é recente, esta modalidade de curso no Brasil tem se expandido, justamente pelo motivo de abarcar um quantitativo expressivo de cursos que não necessitam de infraestrutura e que, por sua vez, não oneram tanto as instituições que irão oferta-los. É comum em universidades a distância cursos direcionados a formação de professores.

A Universidade Federal do Oeste da Bahia foi criada a partir da lei $n^{\circ}$ 12.825, sancionada pela presidenta Dilma Rousseff em 05 de junho de 2013, cerimonia a qual ocorreu no Palácio do Planalto em Brasília. Anterior a UFOB existia em Barreiras o Instituto de Ciências Ambientais e Desenvolvimento Sustentável - ICADS, pertencente a Universidade Federal da Bahia - UFBA, implantado em 2006, no antigo Colégio Padre Vieira, em que atualmente funciona a Reitoria da UFOB. Essa discussão pode ser ilustrada a partir da análise das fotos 13 e 14 da mencionada instituição.

Foto $13-$ UFOB.

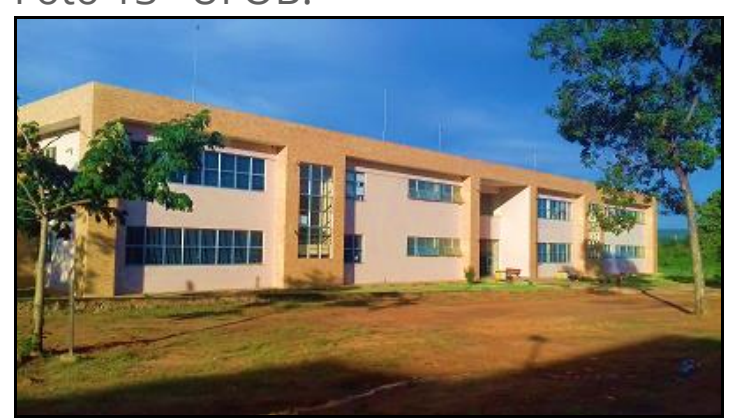

Fonte: Acervo da autora, 2019.
Foto 14- UFOB.

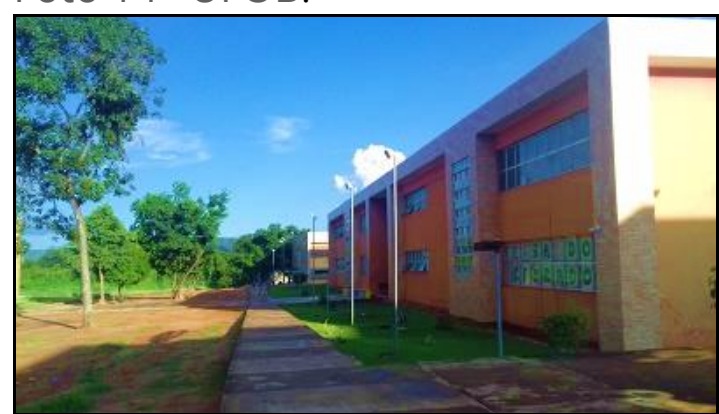

Fonte: Acervo da autora, 2019.

As Instituições de Ensino Superior (IES) na cidade de Barreiras contribuem significantemente para o desenvolvimento regional, pois influenciam na geração de renda e empregabilidade, além de se destacar economicamente, possibilita uma interação entre a população flutuante, que pode ser identificada como indivíduos presentes no território por determinado período de tempo. Sendo assim, o seu crescimento fez com que se tornasse referência em comércios, órgãos públicos e, em relação a educação, em especial a superior, algo que pode ser analisado a partir da quantidade de IES territorializadas. Vieira (2017) salienta que essas IES não corroboram somente para a produção de conhecimento 
científico, como também aquece a economia local, tendo em vista que essas mudanças afetam o mercado de trabalho. Neste sentido, novas inovações podem ser estabelecidas fazendo com que ocorra relação entre Universidades e sociedade.

\section{CONSIDERAÇÕES FINAIS}

As características descritas anteriormente são relevantes no sentido de se entender que para o desenvolvimento de uma cidade é necessário antes de tudo o crescimento econômico, demanda de oferta e serviços, e intercâmbio de mercadorias. Toda cidade é do ponto de vista geoeconômico, um local que oferece bens e serviços, simples ou sofisticados e isso irá depender da renda populacional e das cidades que compõe a região.

Portanto, verifica-se que $57 \%$ da demanda estão matriculados na rede pública de ensino, e 43\% estão matriculados na rede privada. Desta forma, podese compreender que as IES públicas possuem um maior quantitativo de estudantes matriculados. Tendo em vista os respectivos dados com relação a porcentagem, verifica-se a importância das IES na cidade de Barreiras, sendo de cunho público ou privado, é necessário pontuar a relevância, pois ambas contribuem para o desenvolvimento socioeconômico da cidade como também para região Oeste da Bahia.

A percepção com relação a demanda dos cursos pesquisados, faz com que haja uma identificação simultânea entre a modalidade bacharelado e licenciatura, indicando a importância de integrá-los na sociedade, colocando em ênfase determinados cursos superiores, evidenciando a necessidade de demanda e oferta de vagas direcionadas a formação docente, para que haja uma 
expressividade no que se diz respeito a graduandos e formandos em Licenciaturas na cidade de Barreiras.

A cidade de Barreiras vem se posicionando como um polo de Ensino Superior, haja vista o crescimento que a cidade obteve nas últimas décadas, desenvolvimento a qual possibilitou a implantação de universidades públicas e privadas. Analisar essa expansão e interiorização, dar-se-á possibilidades de entender a importância das IES, seja na zona urbana ou rural, essas instituições tem beneficiado a população local, e os demais municípios do Oeste da Bahia. Tendo em consideração que Barreiras constitui de um território que abrange inúmeras instituições, colocando-a como referência no Oeste Baiano. Abaixo pode ser analisado o gráfico 12, com dados referentes as IES públicas e privadas.

\section{Grafico12- Quantitativo de Estudantes Matriculados em Instituições de IES Públicas}

e Privadas na Cidade de Barreiras Para o Ano de 2018.

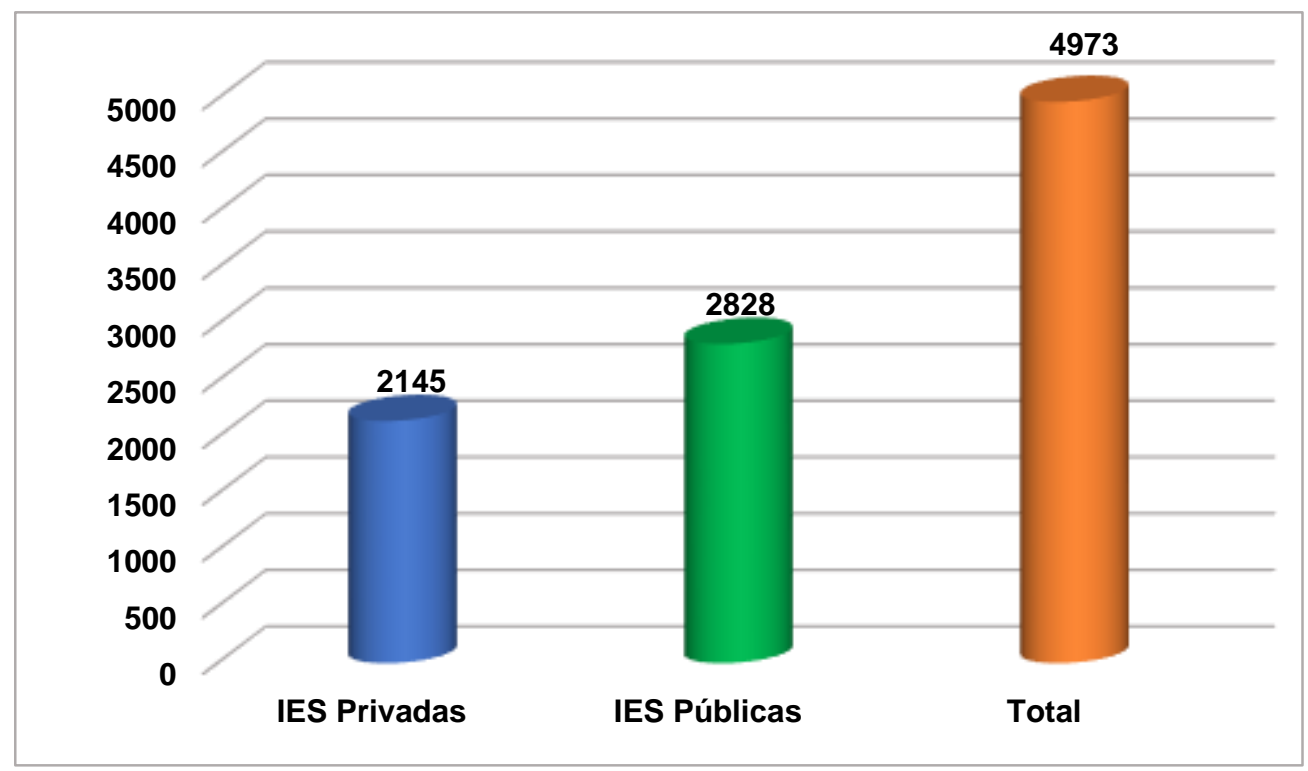

Fonte: IFBA, UNEB, UFOB, UNOPAR, UNIRB, FASB, FACULDADE D. PEDRO II. Pesquisa de campo, 2018. Org.: Elisama Santos, 2019. 
Quando se analisa dados referentes a Educação Superior no Brasil, ver-se que os números de matriculados na modalidade Bacharel é excedente aos números de vinculados a cursos de Licenciatura. Todavia, ressalta-se que nas IES a quantidade de cursos de Bacharelado é maior em relação aos da Licenciatura, neste sentido, estes formam mais estudantes. Em Barreiras não é diferente, pois os cursos que possuem maiores demandas são Direito, Engenharias, Administração, Agronomia e Medicina, ou seja, os com habilitações em bacharéis. Assim sendo, os cincos cursos destacados acima são encontrados na rede pública de Ensino Superior, como também na privada.

Além disso, a presença das IES na cidade vem contribuindo para a formação acadêmica de moradores locais fazendo com que haja a permanência da população residente na cidade, pois se tornarão aptas a exercerem profissões em setores especializados da sociedade barreirense. Assim, a presença das universidades, como também a inserção da população local nas referidas instituições fortalece não apenas a economia local, mas empodera os setores sociais no sentido de dotar a cidade de uma série de atendimentos em áreas específicas que até então só eram encontrados nos centros metropolitanos do país. Sendo assim, a cidade de Barreiras tem se tornado um polo de Ensino Superior na Região Oeste da Bahia, concentrando várias IES de cunho público e privado.

Acima apresentou-se um gráfico contendo o quantitativo de estudantes matriculados nas IES na cidade em tela, todavia abaixo apresenta-se o gráfico 13 com os quantitativos percentuais de matrículas por cursos específicos. Quando se analisa o curso de Geografia na cidade, ver-se que o mesmo é menos demandado com apenas 2\%, com um total e 105 matrículas. 
Gráfico 13- Percentual de Matrículas de Estudantes em Cursos na Cidade de Barreiras e Oeste da Bahia.

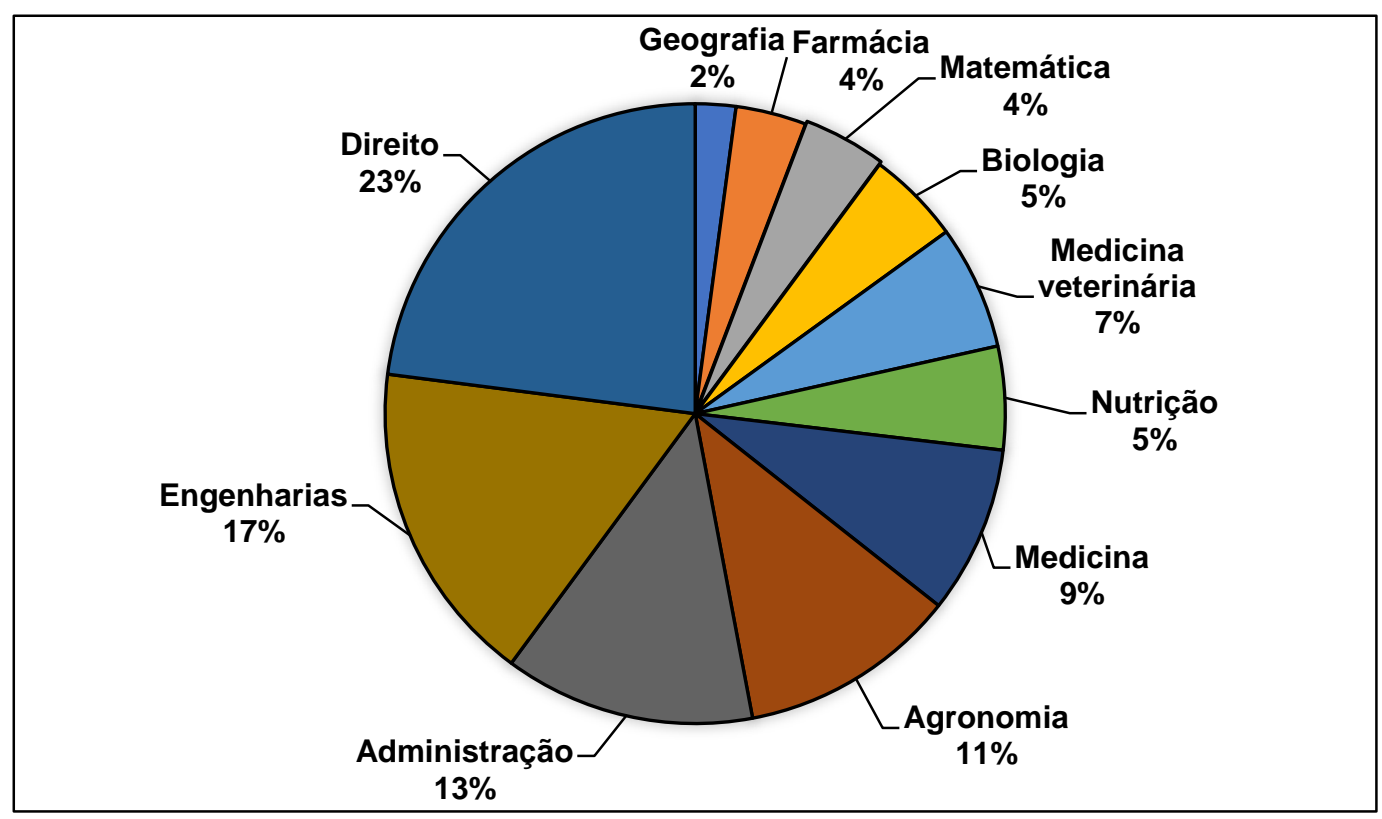

Fonte: IFBA, UNEB, UFOB, UNOPAR, UNIRB, FASB, FACULDADE D. PEDRO II. Pesquisa de campo, 2018. Org.: Elisama Santos, 2019.

Em relação ao curso de direito que representa um percentual de $23 \%$, com 1.142 matriculados, curso a qual possui um maior número de matrículas na cidade. O segundo curso mais demandado na região são os cursos de engenharias, apresentando um total de 17\%, com 842 matriculados, que por sua vez tem adquirido um patamar de representatividade não só na cidade de Barreiras, como também nos municípios em que a UFOB está implantada.

Pode-se analisar a quantidades de IES territorializadas no Oeste da Bahia e em dois municípios da mesorregião do Vale Sanfranciscano, ficando visível que a cidade de Barreiras pode ser considerada um polo de Ensino Superior, sendo a única que possui um quantitativo expressivo de Instituições. Entender o processo de interiorização e expansão dos cursos e Instituições de Ensino Superior na cidade de Barreiras, é relevante pois essa dinamização com relação a produção de conhecimentos, tecnologia e ciência, alçará debates que envolvam questões vinculadas a sociedade (desigualdades sociais, racismo, políticas 
públicas, conflitos territoriais). Conhecimentos e discussões que proporcionarão um empoderamento com relação a educação no Oeste da Bahia.

Sendo assim, comparando o quantitativo de IES na cidade de Barreiras e demais municípios, ver-se que se tornou um polo desenvolvimentista quando se verifica a questão da hegemonia da referida cidade. Deste modo, o Ensino Superior tem possibilitado formação para aqueles que necessitam de obter diploma superior, e as IES que estão territorializadas dispõe de cursos, infraestrutura e corpo docente amplamente qualificado, a exemplo as universidades públicas presente na cidade, que são demandadas não só no limite municipal e regional, mas também por diversos municípios da Bahia e estados do território Brasileiro.

\section{REFERÊNCIAS}

ALMEIDA, S.S. A importância do FIES na garantia do direito ao Ensino Superior. In: XV Colóquio Internacional de Gestão Universitária (Desafios da gestão universitária no século XXI). Anais [...]. Mar Del Prata - Argentina, 2, 3, 4 de dezembro de 2015. Disponível

em: https://repositorio.ufsc.br/bitstream/handle/123456789/136212/102 00204.pdf?sequ ence=1 Acesso em: 10 fev. 2019.

CARVALHO, A.J. ESTÁGIO SUPERVISIONADO E NARRATIVAS (AUTO) BIOGRÁFICAS: Experiências de formação docente. 2008. Dissertação (Mestrado em Educação). Universidade do Estado da Bahia, Salvador - BA, 2008.

FREIRE, H. P.; HOLANDA, V. C. C. A EXPANSÃO DO ENSINO SUPERIOR NAS CIDADES MÉDIAS DO NORDESTE BRASILEIRO. In: XVIII Encontro Nacional de Geógrafos, 2016, São Luís, 24 a 30 de julho. Anais [...]. 2016. Disponível em: http://www.eng2016.agb.org.br/resources/anais/7/1467641437 ARQUIVO ArtigoENG Maranhao.pdf. Acesso em: 5 mar. 2019.

FREIRE H. P.; HOLANDA, V. C. C. A expansão do Ensino Superior nas cidades médias do Nordeste brasileiro. In.: Rejane Maria Gomes da Silva, Virginia Célia Cavalcante de Holanda (Org.) A expansão do Ensino Superior em debate. 1. ed. - Sobral: edições UVA, Editora Sertão Cult, 2018.

GIL, C. A. Métodos e técnicas de pesquisa social. 6. Ed. São Paulo: Editora Atlas, 2008. 
GOEBEL, M. A.; MIURA, M. N. A universidade como fator de desenvolvimento: O caso do município de Toledo - PR. Revista expectativa, Toledo - Paraná, v.3, nº1, p. 36 47, 2004. Disponível em: http://erevista.unioeste.br/index.php/expectativa/article/view/743. Acesso em: 10 fev. 2019.

IBGE - Instituto Brasileiro de Geografia e Estatística. Censo 2010. População do Brasil é de 190.732.694 pessoas. Disponível em: https://censo2010.ibge.gov.br/noticiascenso.html?busca=1\&id=3\&idnoticia=1766\&t=c enso-2010-populacao-brasil-190-732-694-pessoas\&view=noticia. Acesso em: 1 abr. 2019.

IBGE - Instituto Brasileiro de Geografia e Estatística. Censo 2010. Total população de Amazonas. Disponível em: https://www.ibge.gov.br/estatisticas/downloadsestatisticas.html. Acesso em: 1 dez. 2018.

IBGE - Instituto Brasileiro de Geografia e Estatística. Censo 2010. Total população de São Paulo. Disponível em: https://www.ibge.gov.br/estatisticas/downloadsestatisticas.html. Acesso em: 22 dez. 2018.

IBGE- Instituto Brasileiro de Geografia e Estatística. Censo 2010. Total população de Barreiras I Rural e Urbano. Disponível em: https://www.ibge.gov.br/estatisticas/downloads-estatisticas.html. Acesso em: 23 dez. 2018.

INEP - Instituto Nacional de Estudos e Pesquisas Educacionais Anísio Teixeira. (Censo da Educação Superior - 2018) Disponível em: http://portal.inep.gov.br/web/guest/censo-da-educacao-superior. Acesso em: 22 dez. 2018.

SANTOS, M. Técnica, espaço, tempo: Globalização e meio técnico-científico informacional. 5. Ed. São Paulo: Editora da Universidade de São Paulo - USP, 2008.

SAMPAIO, H. Evolução do Ensino Superior brasileiro (1808 - 1990). Núcleo de pesquisa sobre Ensino Superior da universidade de São Paulo - NUPES/USP, p. 130, 1991. Disponível em: http://nupps.usp.br/downloads/docs/dt9108.pdf. Acesso em: 10 fev. 2019.

ULIANA, E.R. Histórico do curso de ciências biológicas no Brasil e em Mato Grosso. In: VI Colóquio Internacional Educação e Contemporaneidade. São Cristóvão - SE/ Brasil, 20, 21 e 22 de setembro de 2012. Disponível em: http://educonse.com.br/2012/eixo 06/PDF/34.pdf. Acesso em: 5 mar. 2019.

VIEIRA, D. J. Evolução do Ensino Superior Brasileiro em período recente: novas perspectivas para o desenvolvimento regional? In: NETO, Aristides Monteiro, CASTRO, César Nunes de, BRANDÃO, Carlos Antônio (Org.). Desenvolvimento Regional no Brasil: políticas, estratégias e perspectivas. Rio de Janeiro: Ipea, 2017. Disponível 
em:

http://www.ipea.gov.br/portal/index.php?option=com content\&view=article\&id=2941 2. Acesso em: 4 mar. 2019. 